\title{
Experimental and modelling studies of neodymium solvent extraction from chloride media with methyl-tri(octyl/decyl)ammonium oleate ionic liquid diluted in kerosene
}

\author{
E. Obón ${ }^{\mathrm{a}}$, A. Fortuny ${ }^{\mathrm{a}}$, M.T. Coll ${ }^{\mathrm{a}}$, A.M. Sastre ${ }^{\mathrm{b}, *}$ \\ ${ }^{a}$ Chemical Engineering Department, Universitat Politècnica de Catalunya, EPSEVG, Av. Víctor Balaguer 1, 08800 Vilanova i la Geltrú, Spain \\ ${ }^{\mathrm{b}}$ Chemical Engineering Department, Universitat Politècnica de Catalunya, ESTEIB, Av. Diagonal 647, 08028 Barcelona, Spain
}

\section{A R T I C L E IN F O}

Keywords:

Neodymium

Chloride media

AliOle IL

Extraction model

\begin{abstract}
A B S T R A C T
A study of the solvent extraction process of $\mathrm{Nd}(\mathrm{III})$ from chloride solutions has been carried out using an ionic liquid (AliOle) prepared from Aliquat 336 (Methyl-tri(octyl/decyl)ammonium chloride) and Oleic Acid. The IL was chosen among other homemade ionic liquids and commercial extractants due to its high Nd(III) extraction ability and good phase separation. Increasing AliOle concentration improves the extraction of $\mathrm{Nd}(\mathrm{III})$ as expected. The $\mathrm{pH}$ of the aqueous phase strongly influences the extraction process. The appropriate equilibrium $\mathrm{pH}$ region has been established in the range 5-6.5. The effect of chloride concentration in the aqueous phase has been investigated. High concentrations of $\mathrm{Cl}^{-}$anion contribute to increasing the extraction yield by promoting neodymium(III) speciation in the aqueous phase.

Two extraction models are proposed from experimental data. Chloride concentration in the aqueous phase determines the $\mathrm{Nd}(\mathrm{III})$ extraction mechanism. The models consider extraction of $\mathrm{Nd}^{3}+$ species when chloride concentration in the solution is low and $\mathrm{NdCl}^{2}+$ species when chloride concentration is high. Competitive extraction between $\mathrm{HCl}$ and the metal ions is also included in the models. They are able to reproduce feasibly the experimental $\mathrm{Nd}(\mathrm{III})$ extraction extension.
\end{abstract}

\section{Introduction}

Rare Earth Elements (REEs) have become necessaries in recent years because of their key role in the development of green technologies and many current domestic products. They have unique chemical features, like their magnetism and optical properties that make them essential for the production of hybrid cars, NiHM batteries, wind turbines, compact fluorescent lamps (CFLs), fluorescent lightning, liquid crystal displays (LCDs) and lasers, among other products (European Commission, 2014a, 2014b; Wang et al., 2015).

Rare earths are conventionally split into two groups: the light group and the heavy group (Smith Stegen, 2015). Light rare earths are more common in nature than heavy rare earths (Panda et al., 2012). They are used in a great variety of applications adapted to new aspects of modern life, culture and current industrial sectors like: innovative ways of green energy generation, production of new materials and aerospace and electronics applications (Wang et al., 2015). Neodymium is one of the most abundant light rare earth elements and it is the raw material for the high-strength permanent magnets (Nd-B-Fe) manufacture which is more affordable than the Sm-Co ones (Banda et al., 2015; Lee et al., 2005).

The growing popularity of mundane products that contain rare earth elements has generated an increase in the demand and the price of these metals. Unfortunately, REEs have the highest supply risk among the rest of chemical elements according to the European Rare Earths Competency Network (ERECON) and their critical status is strongly tied to their heterogeneous geological location, their low concentration in the ores and the environmental issues related to their mining (European Commission, 2014a, 2014b, 2010; Wübbeke, 2013; Zhang et al., 2015). Faced with this problem, the recycling of end-of-life products containing rare earth elements, also called urban mining, is proposed for their recovery and reutilization (Tunsu et al., 2015). Recycling of REEs could become a significant source of these metals for Europe due to the high amount of technological waste generated every year through the large consumption of automotive, electrical and electronic devices that contain rare earths. In the beginning of the present decade, the recycling rates for REEs were reported to be $<1 \%$ of the

\footnotetext{
* Corresponding author.

Email address: ana.maria.sastre@upc.edu (A.M. Sastre)
} 
global supply because of the absence of information about the amount of REEs susceptible to being recycled, low and non-selective collection rates and the non-easy recycling design of the REEs containing products that make the separation of the components difficult (European Commission, 2014a, 2014b). Those barriers need to be broken for the establishment of a commercially viable recycling rate of REEs. Recycling of end-of-life products such as permanent magnets (PMs) from hard drive disks, automotive applications or wind turbines could become a cheap source of REEs and, at the same time, decrease the environmental footprint on the conventional primary mining (Behera and Parhi, 2016; Dupont and Binnemans, 2015; Itoh et al., 2009; Vander Hoogerstraete et al., 2014). Urban mining of PMs which contain about $25 \%$ of $\mathrm{Nd}(\mathrm{III})$ (Vander Hoogerstraete et al., 2014) has become increasingly interesting in the recent years. One of the potential mechanisms that have been tested for the recovery of $\mathrm{Nd}(\mathrm{III})$ from leaching streams is the solvent extraction (Yoon et al., 2016).

Ionic liquids (ILs) are typically organic salts that consist entirely of ions. Its appear to be a good alternative for conventional solvents in extraction processes. Due to their unique features, such as their thermal stability, low vapour pressure, unusual solvent properties, liquid crystalline structures, high electro-elasticity, high heat capacity and non-flammability among others, ionic liquids have been increasingly applied in several chemical fields (Cevasco and Chiappe, 2014).They can be used for separation of REEs by liquid-liquid extraction or membrane processes, being able to extract metals by ion exchange (either cationic or anionic species) as well as by solvation. Moreover, ionic liquids are formed by anions and cations that can be chosen depending on the solute, which should result in a higher selectivity (Rout and Binnemans, 2015; Xie et al., 2014).

\subsection{Background}

Several studies have been done for the separation of neodymium from the aqueous phase by solvent extraction using conventional solvents. The extraction of neodymium(III) from acidic nitrate medium using Cyanex 921 in kerosene was studied by Panda et al. (2012). $98 \%$ extraction of neodymium(III) in $\mathrm{NO}_{3}{ }^{-}$presence was achieved with $0.5 \mathrm{~mol} \cdot \mathrm{L}^{-1}$ Cyanex 921 by forming the organic complex $\mathrm{Nd}\left(\mathrm{NO}_{3}\right)_{3}$. (Cyanex 921) $)_{2}$. Liquid-liquid extraction of neodymium and lanthanum from aqueous nitric acid solutions using a mixture of trioctylphosphine oxides (TOPO) and trialkylphosphine oxide (TRPO) in kerosene was investigated by El-Nadi (2012) obtaining about 95\% extraction of $\mathrm{Nd}$ and $80 \%$ extraction of lanthanum. The extraction complexes found for both metals were $\mathrm{M}\left(\mathrm{NO}_{3}\right)_{3}$.(TOPO).(TRPO) where $\mathrm{M}$ refers to the metal ion. Separation of $\mathrm{Nd}(\mathrm{III})$ from mixed chloride solutions with Pr was carried out using PC-88 by Banda et al. (2015). A selective scrubbing step with pure $\mathrm{Nd}(\mathrm{III})$ solution after extraction with PC 88A was needed to achieve the separation of the metals. An innovative extraction method of neodymium ions from monazite leaching via hollow fiber supported liquid membranes (HFSLM) using HEHEPA dissolved in octane as extractant and nitric acid as stripping solution was achieved by Wannachod et al. (2014) about 95\% of Nd transport was obtained.

Moreover, there are also some studies for the separation of neodymium by solvent extraction using ionic liquids. The extraction behaviour of $\mathrm{Nd}(\mathrm{III})$ from nitrate medium by six ionic liquids [C $\left.{ }_{6} \mathrm{mim}\right][\mathrm{DEHP}], \quad\left[\mathrm{C}_{6} \mathrm{mpyr}\right][\mathrm{DEHP}], \quad\left[\mathrm{N}_{4444}\right][\mathrm{DEHP}], \quad\left[\mathrm{C}_{6} \mathrm{mim}\right]\left[\mathrm{NTf}_{2}\right]$, $\left[\mathrm{C}_{6} \mathrm{mpyr}\right]\left[\mathrm{NTf}_{2}\right]$ and $\left[\mathrm{N}_{1444}\right]\left[\mathrm{NTf}_{2}\right]$ was studied by Rout et al. (2013) It was observed that the neodymium extraction was strongly tied to the equilibrium $\mathrm{pH}$. Four synthetized phosphoryl functionalized ionic liquids $\quad\left[\mathrm{Ph}_{3} \mathrm{PC}_{3} \mathrm{P}(\mathrm{Oet})_{2}\right]\left[\mathrm{PF}_{6}\right], \quad\left[\mathrm{Ph}_{3} \mathrm{PC}_{3} \mathrm{PPh}(\mathrm{Oet})\right]\left[\mathrm{PF}_{6}\right]$, $\left[\mathrm{Ph}_{3} \mathrm{PC} 3 \mathrm{P}(\mathrm{Ph})_{2}\right]\left[\mathrm{PF}_{6}\right]$ and $\left[\mathrm{Ph}_{3} \mathrm{PC}_{3} \mathrm{P}(\mathrm{Oet})_{2}\right]\left[\mathrm{NTf}_{2}\right]$ were tested for the extraction of $\mathrm{Nd}(\mathrm{III})$ from nitrate media by Wang et al. (2016). ILs extraction behaviour was tested under many variables and a solvating mechanism was proposed for $\mathrm{Nd}\left(\mathrm{NO}_{3}\right)_{3}$ extraction. A mixture of Cyanex 923 and ionic liquids phases containing the bis(trifluoromethylsulfonyl)imide anion were tested for the extraction of neodymium and some other REEs from nitrate media by Rout and Binnemans (2015). It was found that the extraction efficiency depended strongly on the hydrophilicity of the ionic liquid cation as well as its solubility in the aqueous phase. Ionic liquids with a small hydrophilic cation, like $\left[\mathrm{C}_{4} \mathrm{mim}\right]\left[\mathrm{Tf}_{2} \mathrm{~N}\right]$ extracted $\mathrm{Nd}(\mathrm{III})$ efficiently via an ion-exchange mechanism, however ionic liquids with a hydrophobic cation, like $\left[\mathrm{P}_{66614}\right]\left[\mathrm{Tf}_{2} \mathrm{~N}\right]$ extracted $\mathrm{Nd}(\mathrm{III})$ much less efficiently because the ion-exchange was suppressed by the low solubility of the ionic liquid cation. The extraction behaviour of some REEs among other transition metal ions such as $\mathrm{Fe}^{3+}, \mathrm{Ni}^{2+}$ and $\mathrm{La}^{3}+$ from an aqueous chloride feed solution by the tetraoctylphosphonium oleate IL ( $\left[\mathrm{P}_{8888}\right]$ [oleate]) was investigated as a function of the $\mathrm{pH}$. $\left[\mathrm{P}_{8888}\right.$ ] [oleate] showed a potential for the separation of transition metals from rare earth elements (Parmentier et al., 2015a). The extraction behaviour of $\mathrm{Nd}(\mathrm{III})$ from aqueous solutions by the new functionalized ionic liquid trioctylmethylammonium dioctyldiglycolamate ([A336][DGA]) was investigated by Rout and Binnemans (2014). It was found that the extraction of $\mathrm{Nd}(\mathrm{III})$ from nitrate media was far superior to extraction from chloride media. The extraction stoichiometry indicated the formation of 1:1 complex between [A336][DGA] and the metal ions.

This paper gathers the results of neodymium chloride extraction experiments with some ionic liquids prepared from the quaternary ammonium salt Aliquat336 combined with acid extractants such as Cyanex272 and Decanoic acid. They seem to be very promising since high extraction percentages were achieved using them.

In this paper, the efficiency of AliOle, a synthetized ionic liquid obtained by contacting the quaternary amine Aliquat 336 with oleic acid is tested. As a first step, the $\mathrm{Nd}(\mathrm{III})$ extraction yield using AliOle is compared with the ones obtained by other extractants, some of them commercial and other synthetized at the laboratory. The effect of the $\mathrm{pH}$, the concentration of the extractant and the effect of the chloride concentration in the aqueous phase were investigated. Acidic stripping agents were used to recover the metal loaded in the organic phase. Mathematical modelling of $\mathrm{Nd}(\mathrm{III})$ extraction from chloride media was done. The use of AliOle IL has shown to be a good alternative to recover the neodymium(III) for urban mining.

\section{Experimental procedure}

\subsection{Reagents}

Neodymium chloride stock solutions were prepared dissolving 99.9\% purity $\mathrm{Nd}_{2} \mathrm{O}_{3}$ (Sigma-Aldrich; Ref.228656) by an acidic attack with $\mathrm{HCl}$. To obtain higher concentrations of chloride in the aqueous phase $\mathrm{NaCl}$ was added until the required concentration. The initial $\mathrm{pH}$ of the feed was adjusted to 3.5 with $\mathrm{NaOH}$.

Hydrochloric, nitric, sulfuric and citric acids $0.5 \mathrm{~mol} \cdot \mathrm{L}^{-1}$ were used as stripping agents in order to find the more convenient way to recover the neodymium from the organic phase.

The organic reagents used in this study were Cyphos 104 (trihexyl(tetradecyl)phosphonium bis-2,4,4-(trimethylpentyl)phosphinate, 93.7\%), Cyanex 923 (a mixture of trialkylphosphine oxides, 93\%) and Cyanex 272 (Bis(2,4,4-trimethylpentyl)phosphinic acid, 85\%) gently provided by Cytec Canada INC.; TBP (tributylphosphate, 99\%) provided by Merck (Ref. 1,000,022,500), D2EHPA (bis(2-ethylhexyl)phosphoric acid, 95\%) and Aliquat 336 (Methyl-tri(octyl/decyl)ammonium chloride, 90.6\%) provided by Alfa Aesar (Ref. 17,723 and A17247, respectively) and Oleic Acid (Cis-9-Octadecenoic acid) provided by Fluka Analytical (Ref. 75,096).

As extractant, AliOle IL was prepared by reacting Aliquat 336 with an equimolar amount of Oleic Acid. It was synthetized by following the procedure established in previous research (Coll et al., 2014; Fortuny et al., 2012). Reactions (R1) and (R2) summarize the synthesis of the extractant. Aliquat $336\left(\overline{\mathrm{R}_{4} \mathrm{~N}^{+} \mathrm{Cl}^{-}}\right)$provided the cationic part of the ionic liquid and the Oleic Acid $(\overline{\mathrm{HA}})$ the anionic part. The bar over the 
species denotes that they are in the organic phase.

$\overline{\mathrm{R}_{4} \mathrm{~N}^{+} \mathrm{Cl}^{-}}+\overline{\mathrm{HA}} \rightarrow \overline{\mathrm{R}_{4} \mathrm{~N}^{+} \mathrm{A}^{-} \cdot \mathrm{HCl}}$

During the reaction $\mathrm{HCl}$ was formed. In order to eliminate it, AliOle was washed with a $0.5 \mathrm{~mol} \cdot \mathrm{L}^{-1} \mathrm{NaHCO}_{3}$ solution until no further $\mathrm{Cl}^{-}$ was present in the aqueous phase.

$$
\begin{aligned}
& \overline{\mathrm{R}_{4} \mathrm{~N}^{+} \mathrm{A}^{-} \cdot \mathrm{HCl}}+\mathrm{NaHCO}_{3} \\
& \rightarrow \overline{\mathrm{R}_{4} \mathrm{~N}^{+} \mathrm{A}^{-}}+\mathrm{NaCl}+\mathrm{H}_{2} \mathrm{O}+\mathrm{CO}_{2}
\end{aligned}
$$

AliCy, AliDec and AliD2EHPA were prepared in the same way as AliOle but using respectively Cyanex 272, Decanoic Acid and D2EHPA as the anionic part.

Table 1 shows the extractants and the concentrations used in the neodymium extraction comparison experiments. Kerosene was used as a diluent and decanol was added as a phase modifier when required.

Different molar concentrations of the commercial solvents were used because it was a first approach to finding which ones are able to extract the neodymium chloride and the dilutions with kerosene were done in volume/volume terms.

\subsection{Procedure}

Extraction experiments were carried out by shaking equal volumes of aqueous and organic phases $(10 \mathrm{~mL})$ in separatory funnels using an MVH-40 SBS horizontal mechanical shaker $(150 \mathrm{rpm})$ at room temperature $\left(21 \pm 2{ }^{\circ} \mathrm{C}\right)$ for $15 \mathrm{~min}$, time enough to achieve the equilibrium (results not shown). After separation, the aqueous phase was collected and its $\mathrm{pH}$ was measured with a calibrated Crison micropH2002 pH meter. Neodymium concentration was determined by Microwave Plasma Atomic Emission Spectroscopy using an MP-AES 4100 spectrophotometer (Agilent Technologies). The organic phases were kept for the stripping experiments.

Eq. 1 was used to calculate neodymium extraction percentages

$\% \mathrm{E}=\frac{[\overline{\mathrm{Nd}}]}{[\mathrm{Nd}]_{\text {ini }}} \cdot 100=\frac{[\mathrm{Nd}]_{\text {ini }}-[\mathrm{Nd}]}{[\mathrm{Nd}]_{\text {ini }}} \cdot 100$

where $[\overline{\mathrm{Nd}}],[\mathrm{Nd}]_{\mathrm{ini}}$ and $[\mathrm{Nd}]$ are the neodymium concentrations in the organic phase, in the feed solution and in the aqueous phase after extraction, respectively.

Acidic stripping solutions were used to close the mass balance and recover the metal loaded in the organic phase after extraction. The stripping experiments were performed in the same way as the extraction experiments. Eq. 2 was used to determine stripping percentages
$\% \mathrm{~S}=\frac{[\mathrm{Nd}]_{\text {strip }}}{[\overline{\mathrm{Nd}}]} \cdot 100$

where $[\mathrm{Nd}]_{\text {strip }}$ is the neodymium concentration in the stripping solution.

The extraction and stripping percentages were calculated from the $\mathrm{Nd}$ (III) concentrations because the O:A ratio was $1: 1$ in all the experiments.

\section{Results and discussion}

\subsection{Screening of extractants}

Chemical characteristics of the extractants play a determining role in its extraction efficiency. Acidic, anionic and solvating extractants as well as the ionic liquids were compared to find which is the most convenient for the Nd(III) extraction. The simplest and most generic expected metal ion extraction mechanisms of the extractants in Table 1 are listed below:

Acidic extractants (Cyanex 272 and Oleic Acid):

$3 \overline{\mathrm{HA}}+\mathrm{Nd}^{3+} \leftrightarrow \overline{\mathrm{NdA}_{3}}+3 \mathrm{H}^{+}$

Solvating extractants (Cyanex 923 and TBP):

$\mathrm{n} \overline{\mathrm{L}}+\mathrm{NdCl}_{3} \leftrightarrow \overline{\mathrm{L}_{\mathrm{n}} \cdot \mathrm{NdCl}_{3}}$

The ionic liquids $\left(\mathrm{R}_{4} \mathrm{~N}^{+} \mathrm{A}^{-}\right)$are able to extract $\mathrm{Nd}(\mathrm{III})$ either by ionic exchange or by solvation. Several Nd-IL extraction mechanisms will be further depicted in the Subsection 3.6 of this paper.

In order to compare the extractants behaviour, some experiments were carried out using neodymium solutions $1000 \mathrm{mg} \cdot \mathrm{L}^{-1}$ in 0.05 and $4 \mathrm{~mol} \cdot \mathrm{L}^{-1}$ chloride media to determine the effect of the anion concentration as well. Fig. 1 shows the neodymium extraction percentages achieved by each extractant.

It can be observed that, the achieved extraction yields with the homemade ionic liquids and Cyphos 104 are greater than the rest of extractants despite the concentrations of the synthetized ILs are lower $\left(0.1 \mathrm{~mol} \cdot \mathrm{L}^{-1}\right)$. All of them extracted near to $100 \%$ of the metal ions. Conversely, Aliquat 336 shows very low extraction compared with the rest of extractants. The IL Aliquat 336 does not extract $\mathrm{Nd}(\mathrm{III})$ for any chloride concentration solutions. This behaviour is related to the metal species extracted. Regarding their features AliD2EHPA, AliCy, AliDec, AliOle and Cyphos 104 can extract both cationic and anionic $\mathrm{Nd}(\mathrm{III})$ species by ion exchange and neutral species by solvation, while Aliquat 336 needs anionic species to extract by exchanging the $\mathrm{Cl}^{-}$. As no neodymium(III) anionic species are formed in chloride media, Aliquat 336 extraction is null. Low extraction values are obtained with TBP as well. It can be noticed that it extracts barely $9 \%$ of the metal ions from $4 \mathrm{~mol} \cdot \mathrm{L}^{-1}$ chloride media. The concentration of TBP used for this com-

Table 1

\begin{tabular}{|c|c|c|c|c|}
\hline Extractant type & $>$ & Concentration & Chemical formula & Name \\
\hline \multirow[t]{6}{*}{ Ionic liquids } & Synthetized & $0.1 \mathrm{M}$ & $\overline{R_{4} N^{+} A^{-}}$ & AliCy \\
\hline & & & & AliDec \\
\hline & & & & AliOle \\
\hline & & & & AliD2EHPA \\
\hline & Commercial & $0.27 \mathrm{M}$ & $\overline{R_{4} P^{+} C y^{-}}$ & Cyphos 104 \\
\hline & & $0.1 \mathrm{M}$ & $\overline{\mathrm{R}_{4} \mathrm{~N}^{+} \mathrm{Cl}^{-}}$ & Aliquat 336 \\
\hline \multirow[t]{4}{*}{ Conventional solvents } & & $0.25 \mathrm{M}$ & $\overline{R_{3} P O}$ & Cyanex 923 \\
\hline & $0.37 \mathrm{M}$ & & $\overline{\mathrm{RO}_{3} \mathrm{PO}}$ & TBP \\
\hline & $0.27 \mathrm{M}$ & & $\overline{H C y}$ & Cyanex 272 \\
\hline & $0.31 \mathrm{M}$ & & $\overline{H A}$ & Oleic Acid \\
\hline
\end{tabular}

Organic extractants used. 


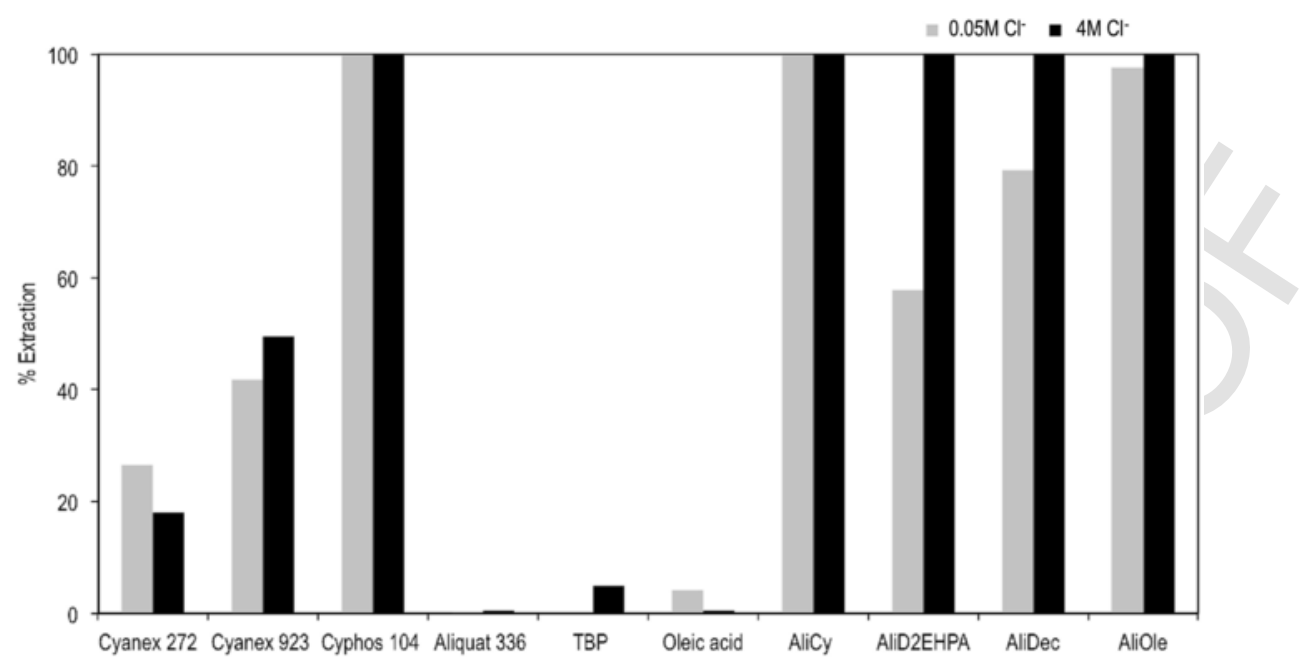

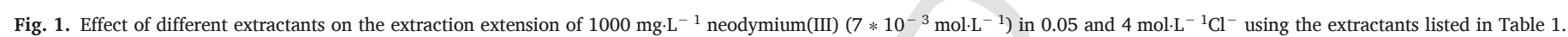

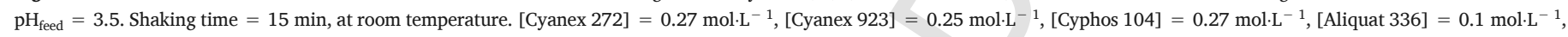
$[\mathrm{TBP}]=0.37 \mathrm{~mol} \cdot \mathrm{L}^{-1}$, [Oleic Acid] $=0.31 \mathrm{~mol} \cdot \mathrm{L}^{-1}$ and $\left[\right.$ synthetized ILs] $=0.1 \mathrm{~mol} \cdot \mathrm{L}^{-1}$.

parison would not be high enough. In this regard, a single experiment with TBP $30 \%_{\mathrm{v} / \mathrm{v}}$ (about $1 \mathrm{~mol} \cdot \mathrm{L}^{-1}$ ) was carried out to evaluate the extraction of $500 \mathrm{mg} \cdot \mathrm{L}^{-1} \mathrm{Nd}(\mathrm{III})$ from $4 \mathrm{~mol} \cdot \mathrm{L}^{-1} \mathrm{Cl}^{-}$aqueous phase and close to $60 \%$ of extraction was achieved.

Solvating extractants, like Cyanex 923 and TBP, show better extraction yields in high chloride media. Increasing chloride concentration in the aqueous phase promotes the formation of neutral species that can be extracted by solvation. The theoretical Nd(III) speciation in the chloride aqueous media can be described as follows:

$\mathrm{Nd}^{3+}+\mathrm{Cl}^{-} \stackrel{\mathrm{K}_{1}}{\leftrightarrow} \mathrm{NdCl}^{2+}$

$\mathrm{NdCl}^{2+}+\mathrm{Cl}^{-} \stackrel{\mathrm{K}_{2}}{\leftrightarrow} \mathrm{NdCl}_{2}^{+}$

$\mathrm{NdCl}_{2}^{+}+\mathrm{Cl}^{-} \stackrel{\mathrm{K}_{3}}{\leftrightarrow} \mathrm{NdCl}_{3}$

The formation constants of Reactions R5, R6 and R7 founded in the literature are listed in Table 2.

Nd(III) extraction with Cyanex 272 is favoured by low chloride concentrations in the aqueous phase. As a cationic extractant, it will extract preferentially $\mathrm{Nd}^{3}+$ species from the media and releases $\mathrm{H}^{+}$acidifying the aqueous phase. As can be observed in Fig. 1, the extraction percentages of $\mathrm{Nd}(\mathrm{III})$ achieved with Oleic Acid are very low compared to the extraction yield of the IL AliOle. This proves the effectiveness of

Table 2

Stability constants in the literature.

\begin{tabular}{llll}
\hline & $\mathrm{Nd}(\mathrm{III})$ & & \\
\hline & $\mathrm{K}_{1}$ & $\mathrm{~K}_{2}$ & $\mathrm{~K}_{3}$ \\
\hline (Puigdomenech, 2013) & 2.09 & 0.50 & - \\
(Högfeldt, 1982) & 1.00 & - & - \\
(Lee et al., 2005) & $8.32 \cdot 10^{-3}$ & - & - \\
(Sastri et al., 2003) & 1.8 & 1.1 & - \\
\hline
\end{tabular}

combining both Aliquat 336 and Oleic Acid for the extraction of neodymium from chloride media.

Since all the synthetized ionic liquids were a good option for a neodymium extraction study, a comparison between AliCy, AliDec, AliD2EHPA and AliOle at lower concentration $\left(0.01 \mathrm{~mol} \cdot \mathrm{L}^{-1}\right)$ was taken to determine the most suitable one for neodymium recovery. Fig. 2 displays the extraction percentages of neodymium obtained by the synthetized ionic liquids.

AliOle was chosen to continue the study among the rest of ionic liquids, even though they achieved similar extraction percentages, due to its faster phase separation.

The high extraction yields showed by ILs could be explained by how they interact with $\mathrm{Nd}(\mathrm{III})$ species. Taking into account the chemical equilibrium diagrams represented in Fig. 3, obtained using the Medusa software (KHT Royal Institute of Technology) (Puigdomenech, 2013), for $1000 \mathrm{mg} \cdot \mathrm{L}^{-1} \mathrm{Nd}(\mathrm{III})$ in 0.05 and $4 \mathrm{~mol} \cdot \mathrm{L}^{-1} \mathrm{Cl}^{-}$media, the metal species that may be formed theoretically in the aqueous phase were $\mathrm{Nd}^{3}{ }^{+}, \mathrm{NdCl}^{2}{ }^{+}$and $\mathrm{NdCl}_{2}{ }^{+}$. However, extraction experiments using neutral extractants like Cyanex 923 and TBP showed that they are also able to extract $\mathrm{Nd}(\mathrm{III})$, which means that neutral species have to be formed as well. Configuration features of Cyphos 104 and the synthetized ionic liquids AliCy, AliDec and AliOle allow them to be able to extract all neodymium species available in the aqueous phase. Cationic species are extracted by the anionic part of the ILs and the neutral species are extracted by solvation. Their versatility is one of the main reasons why ionic liquids are considered strategic extractants for the recovery of REEs from aqueous solutions.

The chemical equilibrium diagrams in Fig. 3 allowed us to choose the $\mathrm{pH}$ range to work with because they show the $\mathrm{pH}$ in which nonsoluble neodymium species $\mathrm{Nd}(\mathrm{OH})_{3}$ will appear under the working conditions. According to the diagrams, higher chloride concentrations in the aqueous phase help to increase the $\mathrm{pH}$ in which $\mathrm{Nd}(\mathrm{OH})_{3}$ species is formed.

\subsection{Effect of $p H$}

During the screening of extractants, it was observed that after metal ions extraction with ionic liquids (AliD2EHPA, AliCy, AliDeca, AliOle 


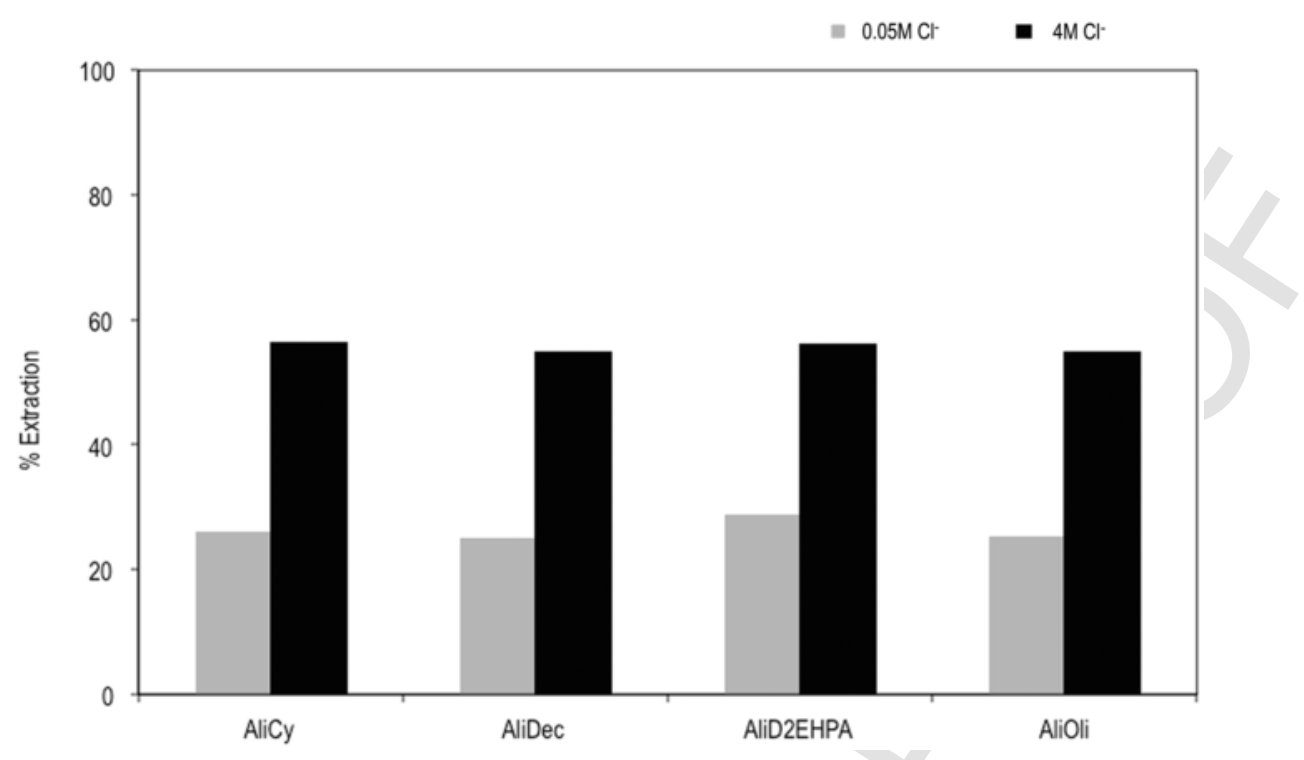

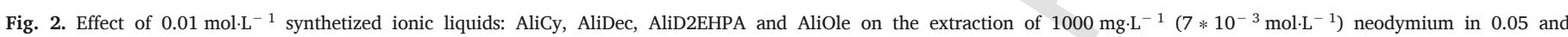
$4 \mathrm{~mol} \cdot \mathrm{L}^{-1} \mathrm{Cl}^{-} \cdot \mathrm{pH}_{\text {feed }}=3.5$. Shaking time $=15 \mathrm{~min}$, at room temperature.

and Cyphos 104) the $\mathrm{pH}$ in the aqueous phase increased from 3.5 until 6.5 approximately. Regarding this observation, a $\mathrm{pH}$ study was carried out to investigate the effect of equilibrium $\mathrm{pH}$ on the neodymium extraction. Fig. 4 shows the percentage of neodymium extraction achieved using $0.025 \mathrm{~mol} \cdot \mathrm{L}^{-1}$ AliOle IL by varying the $\mathrm{pH}$ of the aqueous phase adding $\mathrm{NaOH}$.

As can be seen, the extraction of neodymium with AliOle is strongly influenced by the $\mathrm{pH}$ of the aqueous phase. From equilibrium $\mathrm{pH}$ range 0.5 to 5 , there is not neodymium extraction. Thus, the values that can be observed in the figure can be attributed to the measurement error. This trend is related to the competitive hydrochloric acid extraction. When the initial $\mathrm{H}^{+}$concentration in the aqueous phase is higher than the extractant concentration, only hydrochloric acid is extracted and no further ionic liquid remains available to extract the metal ions. Decreasing $\mathrm{HCl}$ concentration in the aqueous phase releases part of the ionic liquid and the $\mathrm{Nd}(\mathrm{III})$ extraction extension increases.

An inflection point appears between equilibrium pH 5 to 6 (matching up with the Oleic Acid pKa $=4.99$ ) where the $\mathrm{Nd}(\mathrm{III})$ extraction percentages increase significantly because the $\mathrm{H}^{+}$concentration in the aqueous phase decreases under $0.025 \mathrm{~mol} \cdot \mathrm{L}^{-1}$ which is the concentration of the extractant. From pH 6 onwards the recovery of the metal ions keeps increasing until reaching almost $100 \%$. The result is in agreement with the work of Parmentier et al. (2015a) regarding the extraction of REEs by Tetraoctylphosphonium Oleate IL. Nevertheless, it is advisable to keep equilibrium $\mathrm{pH}$ as low as possible to avoid precipitation issues and not to let it increase further than 6.5-7 while working with low chloride concentrations.

An $\mathrm{HCl}$ extraction test was carried out to evaluate $\mathrm{HCl}$ extraction with AliOle. Extractions of $0.39,0.22,0.07$ and $0.04 \mathrm{~mol} \cdot \mathrm{L}^{-1} \mathrm{HCl}$ solutions were done using different concentrations of AliOle from 0 to $0.1 \mathrm{~mol} \cdot \mathrm{L}^{-1}$. A calibrated $\mathrm{pH}$ meter was used to determine the $\mathrm{HCl}$ concentration in the aqueous phase.

As can be observed in the Fig. 5, when $\mathrm{HCl}$ concentration is lower than AliOle concentration, all the acid is extracted neutralizing the solution and showing an acid-extractant ratio of 1:1. Therefore, increasing $\mathrm{pH}$ in the feed solution promotes higher neodymium extraction percentages, since more free extractant remains available to react with metal species.

\subsection{Effect of AliOle concentration}

Experimental studies were performed to determine the effect of the extractant concentration using different aqueous solutions containing $1000 \mathrm{mg} \cdot \mathrm{L}^{-1}$ of neodymium in $0.05,2$ and $4 \mathrm{~mol} \cdot \mathrm{L}^{-1}$ chloride, $\mathrm{pH}_{\text {feed }}=3.5$ and AliOle dissolved in kerosene to obtain concentrations between 0.005 and $0.1 \mathrm{~mol} \cdot \mathrm{L}^{-1}$. Fig. 6 shows the percentages of neodymium extraction achieved and the equilibrium $\mathrm{pH}$ of each experimental series.

As expected, neodymium extraction increases by increasing AliOle concentration. At this point, it can be seen that chloride concentration in the aqueous phase has a visible effect on the metal ions extraction yield. Higher chloride concentration tends to increase neodymium extractability, due to the promotion of the formation of neodymium chloride species in the aqueous phase, at least when using small concentrations of ionic liquid. Thus, it can be observed that the salt concentration in the feed has an impact on the competitive $\mathrm{HCl}$ extraction since higher equilibrium $\mathrm{pH}$ 's were reached with $0.05 \mathrm{~mol} \cdot \mathrm{L}^{-} \mathrm{Cl}^{-}$than with $4 \mathrm{M} \mathrm{Cl}^{-}$ solutions.

\subsection{Effect of chloride concentration}

The extraction experiments of neodymium in $0.05,2$ and $4 \mathrm{~mol} \cdot \mathrm{L}^{-1}$ chloride with AliOle showed that the extraction of the metal ions is related someway with the anion concentration in the aqueous phase. From this comment, an experiment focused on the effect of saline media was carried out to evaluate how chloride concentration in the aqueous phase could influence the extraction process. The increase of the chloride concentration in the aqueous phase was achieved by adding $\mathrm{NaCl}$ to the solution.

Fig. 7 shows the percentages of neodymium(III) extraction achieved with $0.02 \mathrm{~mol} \cdot \mathrm{L}^{-1}$ AliOle by changing $\mathrm{Cl}^{-}$concentration in the feed.

It is observed that increasing chloride concentration enhances the extraction of the metal as expected regarding the first approach in Fig. 6. The extraction percentage of neodymium in $4 \mathrm{~mol} \cdot \mathrm{L}^{-1} \mathrm{Cl}^{-}$(about $82 \%$ ) is near to two times higher than the extraction percentage reached for $0.05 \mathrm{~mol} \cdot \mathrm{L}^{-1} \mathrm{Cl}^{-}(48.6 \%)$. The notable increment of the metal extraction while increasing chloride concentration suggests that the $\mathrm{Nd}(\mathrm{III})$ extracted by AliOle may be chlorinated. 
a.
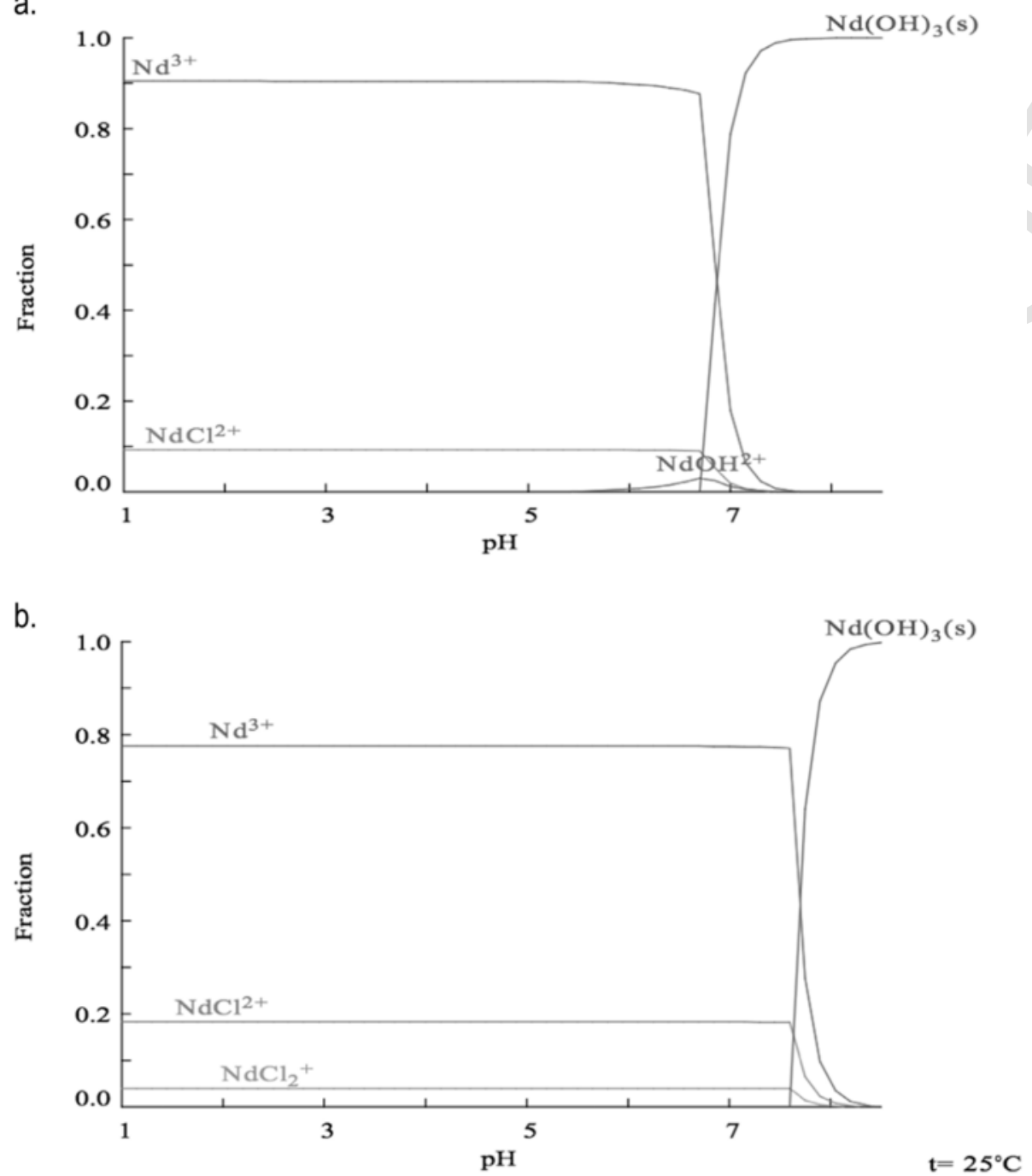

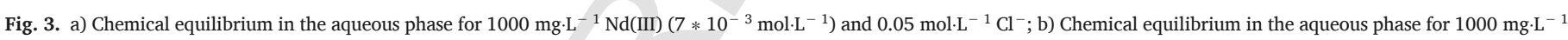
$\mathrm{Nd}(\mathrm{III}), 4 \mathrm{~mol} \cdot \mathrm{L}^{-1} \mathrm{Cl}^{-}$and Ionic strength $=4$. Diagrams were made using Medusa software from KHT Royal Institute of Technology (Puigdomenech, 2013).

Fig. 8 shows the distribution diagram of the neodymium species in the aqueous media using the Medusa software (Puigdomenech, 2013) for $1000 \mathrm{mg} \cdot \mathrm{L}^{-1} \mathrm{Nd}$ (III) by varying chloride concentration.

As can be seen, increasing the chloride concentration promotes the formation of further $\mathrm{Nd}(\mathrm{III})$ species in the aqueous phase available to be extracted by the ionic liquid. Taking into account the equilibrium diagram and comparing it to the experimental results in Fig. 7 it can be assumed that neodymium has to be extracted as a chloride complex. Furthermore, high chloride concentrations in the aqueous phase increase the ionic strength of the media and displaces the precipitation of $\mathrm{Nd}(\mathrm{OH})_{3}$ to a higher $\mathrm{pH}$ as can be observed in Fig. 3 .

\subsection{Extraction model}

Extraction models are proposed from the extraction experimental data. Regarding the chemical equilibrium diagrams in Fig. 3 and taking into account the results in Fig. 1, where neutral extractants are also able to extract the $\mathrm{Nd}(\mathrm{III})$, the theoretical equilibrium IL-Nd(III) reactions that could take place in chloride media are listed below. All these equilibriums consider that the $\mathrm{Nd}(\mathrm{III})$ species extracted is the only one in the aqueous phase.

a.

$$
3 \overline{\mathrm{R}_{4} \mathrm{~N}^{+} \mathrm{A}^{-}}+\mathrm{Nd}^{3+}+3 \mathrm{Cl}^{-} \stackrel{\mathrm{K}_{\mathrm{a}}}{\leftrightarrow} 3 \overline{\mathrm{R}_{4} \mathrm{~N}^{+} \mathrm{Cl}^{-}}+\overline{\mathrm{NdA}_{3}}
$$

$$
\begin{aligned}
\mathrm{K}_{\mathrm{a}} & =\frac{\left[\overline{\mathrm{R}_{4} \mathrm{~N}^{+} \mathrm{Cl}^{-}}\right]^{3} \cdot\left[\overline{\mathrm{NdA}_{3}}\right]}{\left[\overline{\mathrm{R}_{4} \mathrm{~N}^{+} \mathrm{A}^{-}}\right]^{3} \cdot\left[\mathrm{Nd}^{3+}\right] \cdot\left[\mathrm{Cl}^{-}\right]^{3}} \\
& =\frac{\left(3 \cdot[\overline{\mathrm{Nd}}]+\Delta\left[\mathrm{H}^{+}\right]\right)^{3} \cdot[\overline{\mathrm{Nd}}]}{[\mathrm{E}]_{\text {free }}^{3} \cdot[\mathrm{Nd}] \cdot\left[\mathrm{Cl}^{-}\right]^{3}}
\end{aligned}
$$

b.

$$
3 \overline{\mathrm{R}_{4} \mathrm{~N}^{+} \mathrm{A}^{-}}+\mathrm{Nd}^{3+}+3 \mathrm{Cl}^{-} \stackrel{\mathrm{K}_{\mathrm{b}}}{\leftrightarrow} \overline{\left(\mathrm{R}_{4} \mathrm{~N}^{+} \mathrm{Cl}^{-}\right)_{3} \cdot \mathrm{NdA}_{3}}
$$




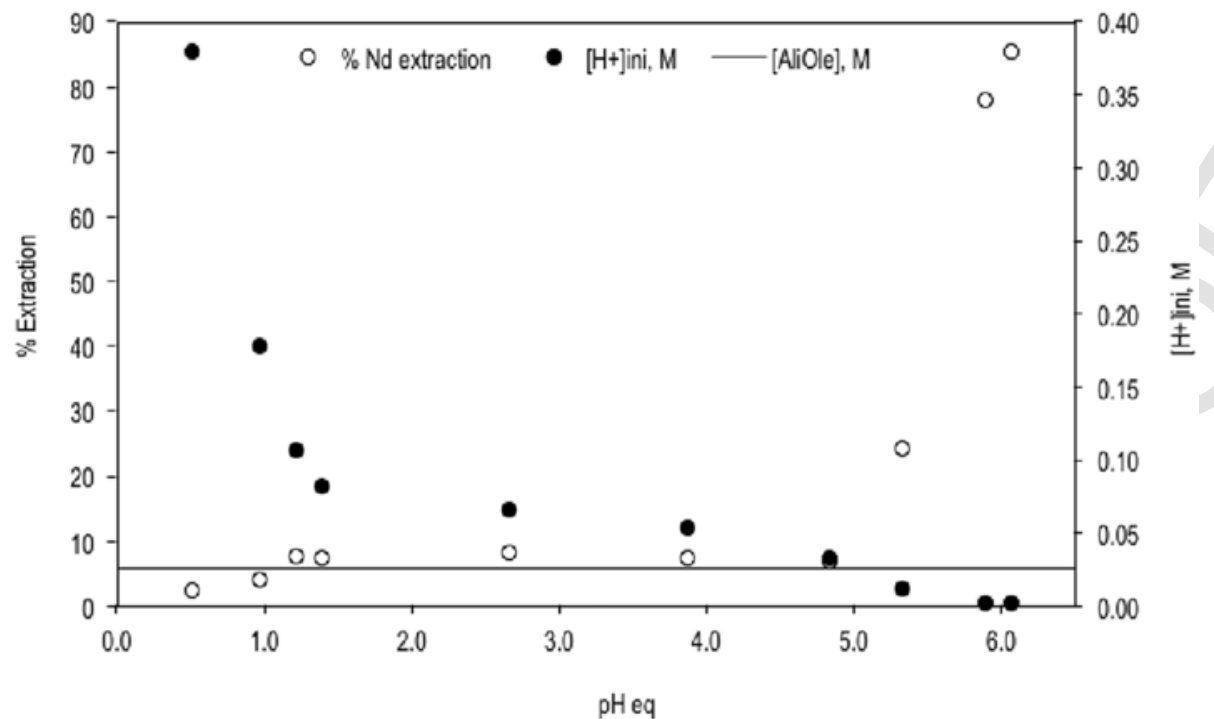

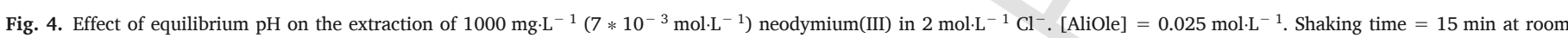
temperature.

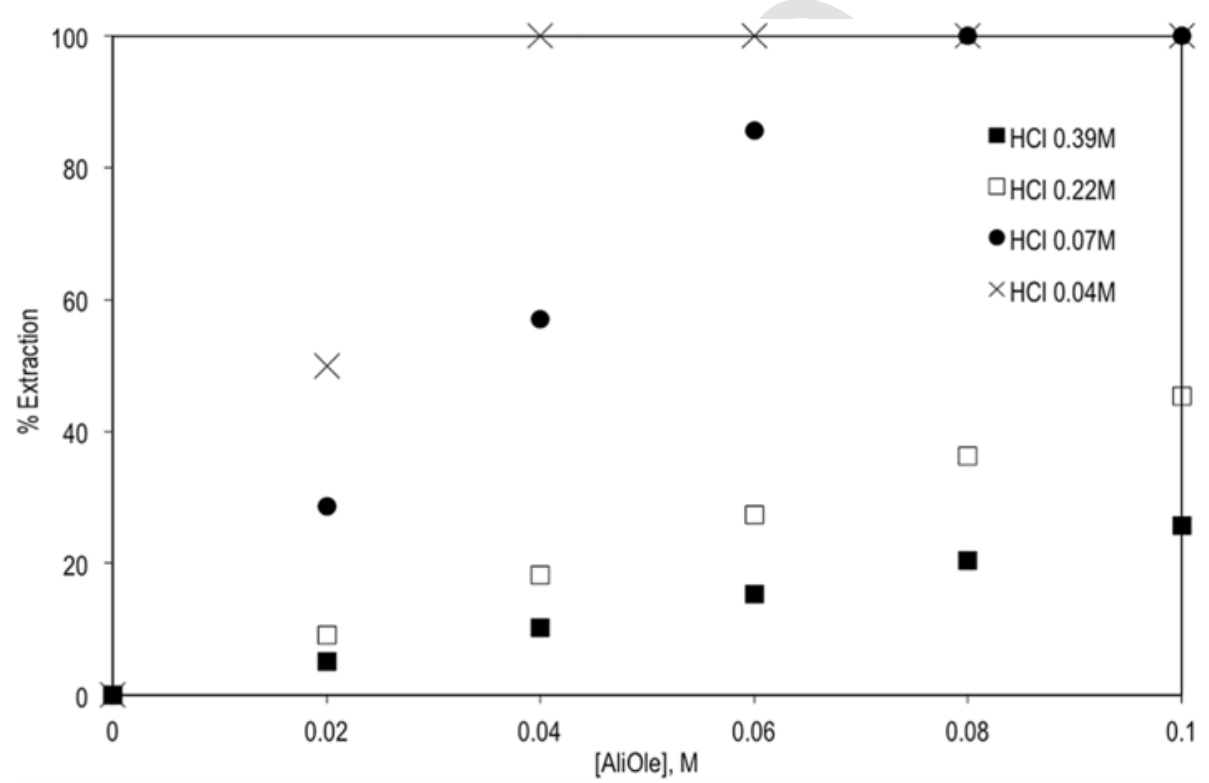

Fig. 5. Effect of AliOle concentration on the extraction of $\mathrm{HCl}$. $[\mathrm{HCl}]=0.39 ; 0.22 ; 0.07 ; 0.04 \mathrm{~mol} \cdot \mathrm{L}^{-1}$. Shaking time $=15 \mathrm{~min}$ at room temperature. 


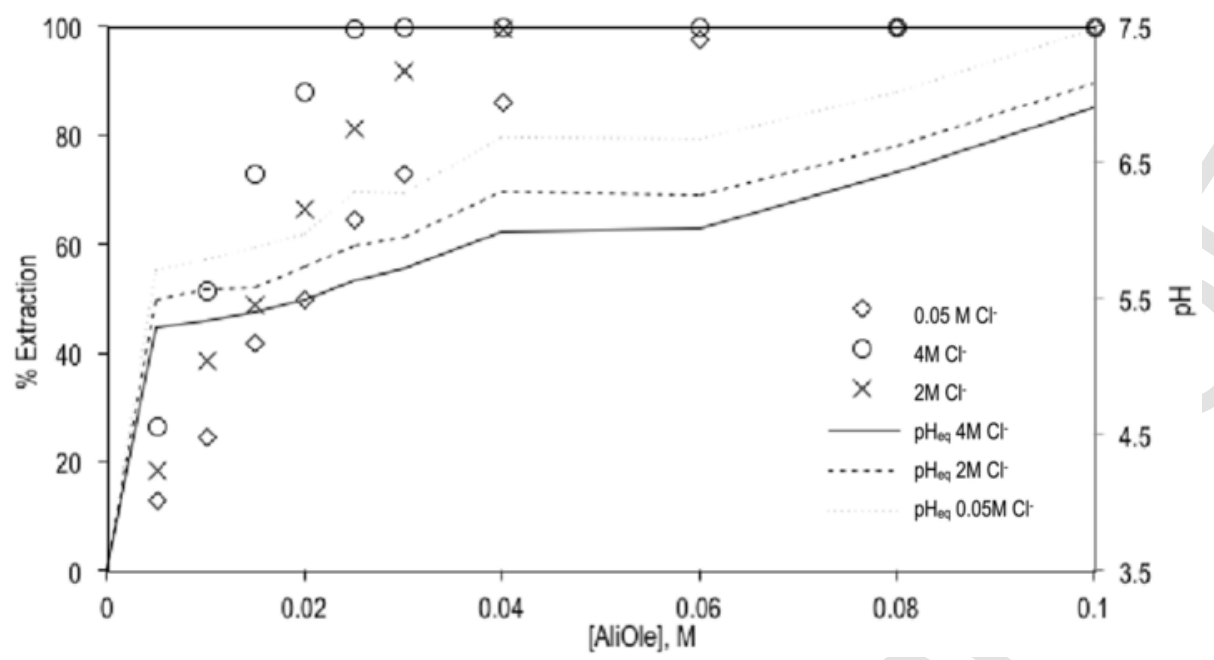

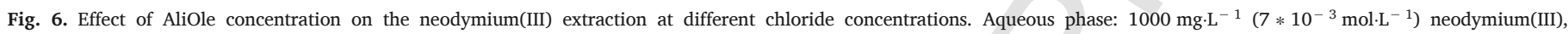
$\left[\mathrm{Cl}^{-}\right]=0.05,2$ and $4 \mathrm{~mol} \cdot \mathrm{L}^{-1}$. Shaking time $=15 \mathrm{~min}$ at room temperature.

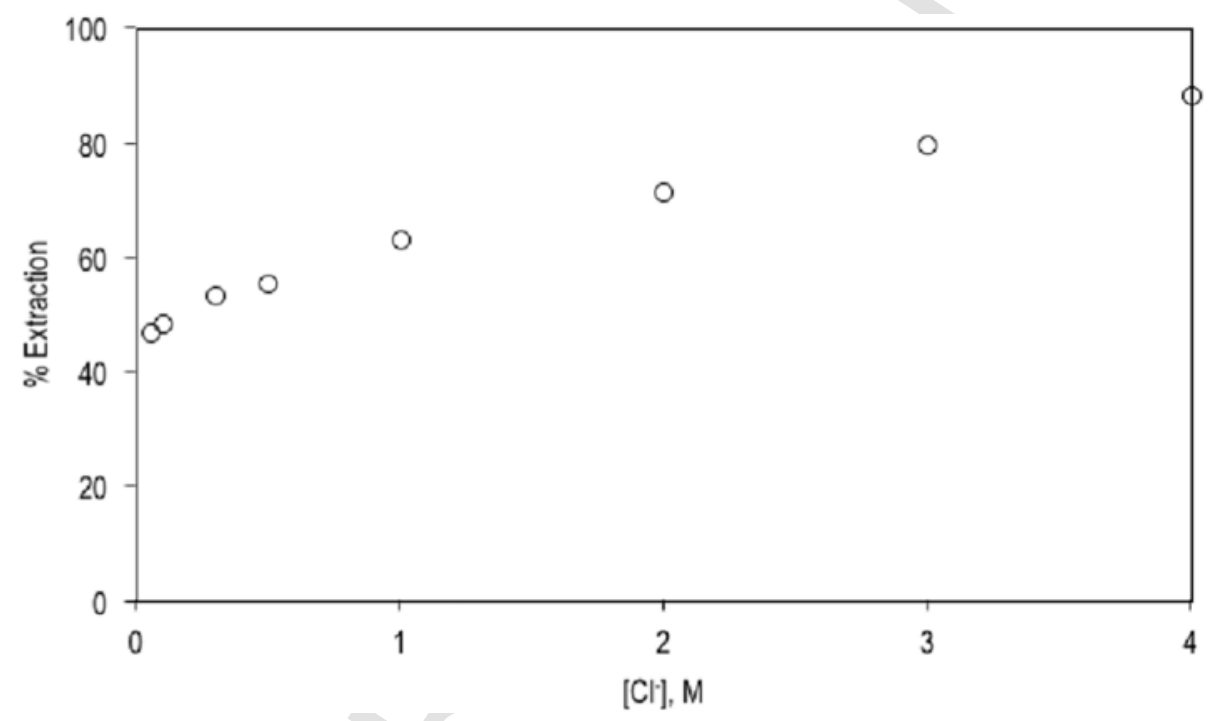

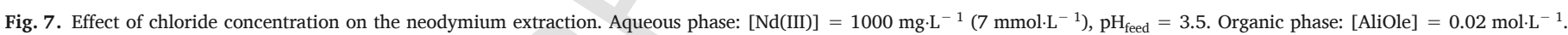
Shaking time $=15 \mathrm{mint}$ at room temperature. 


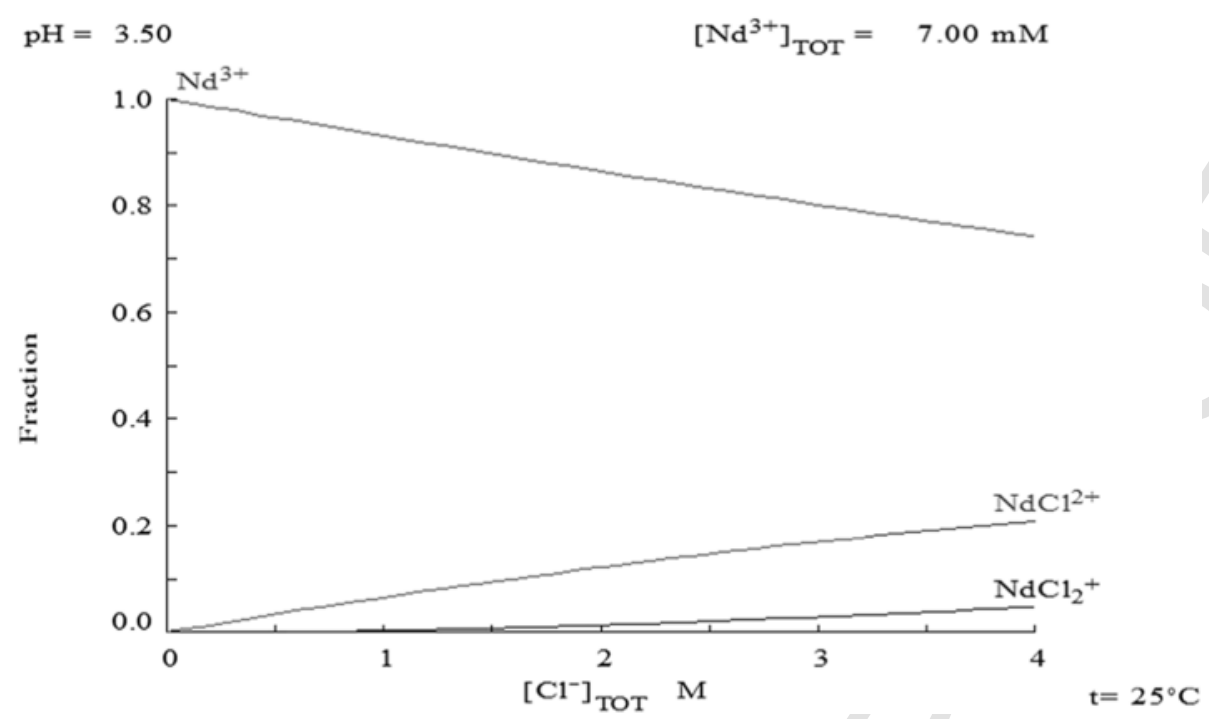

Fig. 8. Effect of the chloride concentration on the $\mathrm{Nd}(\mathrm{III})$ speciation in the aqueous phase. $[\mathrm{Nd}(\mathrm{III})]=1000 \mathrm{mg} \cdot \mathrm{L}^{-1}\left(7 * 10^{-3} \mathrm{~mol} \cdot \mathrm{L}^{-1}\right)$, $\mathrm{pH}=3.5(\mathrm{Puigdomenech}, 2013)$.

$$
\begin{aligned}
& \mathrm{K}_{\mathrm{b}}=\frac{\left[\overline{\left(\mathrm{R}_{4} \mathrm{~N}^{+} \mathrm{Cl}^{-}\right)_{3} \cdot \mathrm{NdA}_{3}}\right]}{\left[\overline{\mathrm{R}_{4} \mathrm{~N}^{+} \mathrm{A}^{-}}\right]^{3} \cdot\left[\mathrm{Nd}^{3+}\right] \cdot\left[\mathrm{Cl}^{-}\right]^{3}} \\
& =\frac{[\overline{\mathrm{Nd}}]}{[\mathrm{E}]_{\mathrm{free}}^{3} \cdot[\mathrm{Nd}] \cdot\left[\mathrm{Cl}^{-}\right]^{3}} \\
& \text { c. } 3 \overline{\mathrm{R}_{4} \mathrm{~N}^{+} \mathrm{A}^{-}}+\mathrm{Nd}^{3+} \\
& +3 \mathrm{Cl}^{-} \stackrel{\mathrm{K}_{\mathrm{c}}}{\leftrightarrow} \overline{\left(\mathrm{R}_{4} \mathrm{~N}^{+} \mathrm{Cl}^{-}\right)_{2} \cdot \mathrm{NdA}_{3}}+\overline{\mathrm{R}_{4} \mathrm{~N}^{+} \mathrm{Cl}^{-}} \\
& \mathrm{K}_{\mathrm{c}}=\frac{\left[\overline{\left(\mathrm{R}_{4} \mathrm{~N}^{+} \mathrm{Cl}^{-}\right)_{2} \cdot \mathrm{NdA}_{3}}\right] \cdot\left[\overline{\mathrm{R}_{4} \mathrm{~N}^{+} \mathrm{Cl}^{-}}\right]}{\left[\overline{\mathrm{R}_{4} \mathrm{~N}^{+} \mathrm{A}^{-}}\right]^{3} \cdot\left[\mathrm{Nd}^{3+}\right] \cdot\left[\mathrm{Cl}^{-}\right]^{3}} \\
& =\frac{[\overline{\mathrm{Nd}}] \cdot\left([\overline{\mathrm{Nd}}]+\Delta\left[\mathrm{H}^{+}\right]\right)}{[\mathrm{E}]_{\mathrm{free}}^{3} \cdot[\mathrm{Nd}] \cdot\left[\mathrm{Cl}^{-}\right]^{3}}
\end{aligned}
$$

e.

$$
2 \overline{\mathrm{R}_{4} \mathrm{~N}^{+} \mathrm{A}^{-}}+\mathrm{NdCl}^{2+}+2 \mathrm{Cl}^{-} \stackrel{\mathrm{K}_{\mathrm{e}}}{\leftrightarrow} 2 \overline{\mathrm{R}_{4} \mathrm{~N}^{+} \mathrm{Cl}^{-}}+\overline{\mathrm{NdClA}_{2}}
$$

$$
\begin{aligned}
\mathrm{K}_{\mathrm{e}} & =\frac{\left[\overline{\mathrm{R}_{4} \mathrm{~N}^{+} \mathrm{Cl}^{-}}\right]^{2} \cdot\left[\overline{\mathrm{NdClA}_{2}}\right]}{\left[\overline{\mathrm{R}_{4} \mathrm{~N}^{+} \mathrm{A}^{-}}\right]^{2} \cdot\left[\mathrm{NdCl}^{2+}\right] \cdot\left[\mathrm{Cl}^{-}\right]^{2}} \\
& =\frac{\left(2 \cdot[\overline{\mathrm{Nd}}]+\Delta\left[\mathrm{H}^{+}\right]\right)^{2} \cdot[\overline{\mathrm{Nd}}]}{[\mathrm{E}]_{\text {free }}^{2} \cdot[\mathrm{Nd}] \cdot\left[\mathrm{Cl}^{-}\right]^{2}}
\end{aligned}
$$

f.

(5)$$
2 \overline{\mathrm{R}_{4} \mathrm{~N}^{+} \mathrm{A}^{-}}+\mathrm{NdCl}^{2+}
$$$$
+2 \mathrm{Cl}^{-} \stackrel{\mathrm{K}_{\mathrm{f}}}{\leftrightarrow} \overline{\left(\mathrm{R}_{4} \mathrm{~N}^{+} \mathrm{Cl}^{-}\right)_{2} \cdot \mathrm{NdClA}_{2}}
$$

(R11)

$$
\begin{aligned}
\mathrm{K}_{\mathrm{f}} & =\frac{\left[\overline{\left(\mathrm{R}_{4} \mathrm{~N}^{+} \mathrm{Cl}^{-}\right)_{2} \cdot \mathrm{NdClA}_{2}}\right]}{\left[\overline{\mathrm{R}_{4} \mathrm{~N}^{+} \mathrm{A}^{-}}\right]^{2} \cdot\left[\mathrm{NdCl}^{2+}\right] \cdot\left[\mathrm{Cl}^{-}\right]^{2}} \\
& =\frac{[\mathrm{Nd}]_{\mathrm{org}}}{[\mathrm{E}]_{\text {free }}^{2} \cdot[\mathrm{Nd}] \cdot\left[\mathrm{Cl}^{-}\right]^{2}} \\
\text { g. } & \overline{\mathrm{R}_{4} \mathrm{~N}^{+} \mathrm{A}^{-}}+\mathrm{NdCl}^{2+} \\
& +2 \mathrm{Cl}^{-} \stackrel{\mathrm{K}_{\mathrm{g}}}{\leftrightarrow} \overline{\mathrm{R}_{4} \mathrm{~N}^{+} \mathrm{Cl}^{-} \cdot \mathrm{NdClA}_{2}}+\overline{R_{4} N^{+} C l^{-}}
\end{aligned}
$$$$
\mathrm{K}_{\mathrm{d}}=\frac{\left[\overline{\mathrm{R}_{4} \mathrm{~N}^{+} \mathrm{Cl}^{-} \cdot \mathrm{NdA}_{3}}\right] \cdot\left[\overline{\mathrm{R}_{4} \mathrm{~N}^{+} \mathrm{Cl}^{-}}\right]^{2}}{\left[\overline{\mathrm{R}_{4} \mathrm{~N}^{+} \mathrm{A}^{-}}\right]^{3} \cdot\left[\mathrm{Nd}^{3+}\right] \cdot\left[\mathrm{Cl}^{-}\right]^{3}}
$$$$
=\frac{[\overline{\mathrm{Nd}}] \cdot\left(2 \cdot[\overline{\mathrm{Nd}}]+\Delta\left[\mathrm{H}^{+}\right]\right)^{2}}{[\mathrm{E}]_{\mathrm{free}}^{3} \cdot[\mathrm{Nd}] \cdot\left[\mathrm{Cl}^{-}\right]^{3}}
$$

(6) 


$$
\begin{aligned}
\mathrm{K}_{\mathrm{g}} & =\frac{\left[\overline{\mathrm{R}_{4} \mathrm{~N}^{+} \mathrm{Cl}^{-} \cdot \mathrm{NdClA}_{2}}\right] \cdot\left[\overline{\mathrm{R}_{4} \mathrm{~N}^{+} \mathrm{Cl}^{-}}\right]}{\left[\overline{\mathrm{R}_{4} \mathrm{~N}^{+} \mathrm{A}^{-}}\right]^{2} \cdot\left[\mathrm{NdCl}^{2+}\right] \cdot\left[\mathrm{Cl}^{-}\right]^{2}} \\
& =\frac{[\overline{\mathrm{Nd}}] \cdot\left([\overline{\mathrm{Nd}}]+\Delta\left[\mathrm{H}^{+}\right]\right)}{[\mathrm{E}]_{\text {free }}^{2} \cdot[\mathrm{Nd}] \cdot\left[\mathrm{Cl}^{-}\right]^{2}}
\end{aligned}
$$

h.

$$
\overline{\mathrm{R}_{4} \mathrm{~N}^{+} \mathrm{A}^{-}}+\mathrm{NdCl}_{2}{ }^{+}+\mathrm{Cl}^{-} \stackrel{\mathrm{K}_{\mathrm{h}}}{\leftrightarrow} \overline{\mathrm{R}_{4} \mathrm{~N}^{+} \mathrm{Cl}^{-}}+\overline{\mathrm{NdCl}_{2} \mathrm{~A}}
$$

$$
\begin{aligned}
\mathrm{K}_{\mathrm{h}} & =\frac{\left[\overline{\mathrm{R}_{4} \mathrm{~N}^{+} \mathrm{Cl}^{-}}\right] \cdot\left[\overline{\mathrm{NdCl}_{2} \mathrm{~A}}\right]}{\left[\overline{\mathrm{R}_{4} \mathrm{~N}^{+} \mathrm{A}^{-}}\right] \cdot\left[\mathrm{NdCl}_{2}^{+}\right] \cdot\left[\mathrm{Cl}^{-}\right]} \\
& =\frac{\left([\overline{\mathrm{Nd}}]+\Delta\left[\mathrm{H}^{+}\right]\right) \cdot[\overline{\mathrm{Nd}}]}{[\mathrm{E}]_{\text {free }} \cdot[\mathrm{Nd}] \cdot\left[\mathrm{Cl}^{-}\right]}
\end{aligned}
$$

i.

$$
\overline{\mathrm{R}_{4} \mathrm{~N}^{+} \mathrm{A}^{-}}+\mathrm{NdCl}_{2}^{+}+\mathrm{Cl}^{-} \stackrel{\mathrm{K}_{\mathrm{i}}}{\leftrightarrow} \overline{\mathrm{R}_{4} \mathrm{~N}^{+} \mathrm{Cl}^{-} \cdot \mathrm{NdCl}_{2} \mathrm{~A}}
$$

$$
\begin{aligned}
\mathrm{K}_{\mathrm{i}} & =\frac{\left[\overline{\mathrm{R}_{4} \mathrm{~N}^{+} \mathrm{Cl}^{-} \cdot \mathrm{NdCl}_{2} \mathrm{~A}}\right]}{\left[\overline{\left.\mathrm{R}_{4} \mathrm{~N}^{+} \mathrm{A}^{-}\right] \cdot\left[\mathrm{NdCl}_{2}+\right] \cdot\left[\mathrm{Cl}^{-}\right]}\right.} \\
& =\frac{[\overline{\mathrm{Nd}}]}{[\mathrm{E}]_{\text {free }} \cdot[\mathrm{Nd}] \cdot\left[\mathrm{Cl}^{-}\right]}
\end{aligned}
$$

j.

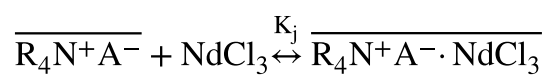

$$
\mathrm{K}_{\mathrm{j}}=\frac{\left[\overline{\mathrm{R}_{4} \mathrm{~N}^{+} \mathrm{A}^{-} \cdot \mathrm{NdCl}_{3}}\right]}{\left[\overline{\left.\mathrm{R}_{4} \mathrm{~N}^{+} \mathrm{A}^{-}\right] \cdot\left[\mathrm{NdCl}_{3}\right]}\right.}=\frac{[\overline{\mathrm{Nd}}]}{[\mathrm{E}]_{\mathrm{free}} \cdot[\mathrm{Nd}]}
$$

The $\mathrm{HCl}$ extraction reaction has to be also taken into account during the mathematical development due to the high impact of the $\mathrm{pH}$ on the extraction process:

$$
\overline{\mathrm{R}_{4} \mathrm{~N}^{+} \mathrm{A}^{-}}+\mathrm{HCl} \stackrel{K e_{H C l}}{\leftrightarrow} \overline{\mathrm{R}_{4} \mathrm{~N}^{+} \mathrm{Cl}^{-}}+\overline{\mathrm{HA}}
$$

Therefore, the variation of protons concentration before and after the extraction $\left(\Delta\left[\mathrm{H}^{+}\right]=\left[\mathrm{H}^{+}\right]_{\text {ini }}-\left[\mathrm{H}^{+}\right]\right)$is considered for the determination of $[E]_{\text {free, }}\left[\mathrm{Cl}^{-}\right]$and $\left[\overline{\mathrm{R}_{4} \mathrm{~N}^{+} \mathrm{Cl}^{-}}\right]$bearing in mind that the Reaction R18 is complete.

In the equations above, $[E]_{\text {free }}$ is the concentration of extractant that remains available after extraction, determined by:

$[\mathrm{E}]_{\text {free }}=[\mathrm{E}]_{\mathrm{ini}}-\mathrm{n} \cdot[\overline{\mathrm{Nd}}]-\Delta\left[\mathrm{H}^{+}\right]$

where $\mathrm{n}$ can be 1,2 or 3 , depending on the reaction's stoichiometry.
$\left[\overline{\mathrm{R}_{4} \mathrm{~N}^{+} \mathrm{Cl}^{-}}\right]$is the chloride concentration in the organic phase extracted from the metal chloride complex and from the hydrochloric acid. It can be represented as:

$\left[\overline{\mathrm{R}_{4} \mathrm{~N}^{+} \mathrm{Cl}^{-}}\right]=\mathrm{p} \cdot[\overline{\mathrm{Nd}}]+\Delta\left[\mathrm{H}^{+}\right]$

where $\mathrm{p}$ is the stoichiometric coefficient of $\left[\overline{\mathrm{R}_{4} \mathrm{~N}^{+} \mathrm{Cl}^{-}}\right]$.

$\left[\mathrm{Cl}^{-}\right]$is the chloride concentration remaining in the aqueous phase after extraction:

$\left[\mathrm{Cl}^{-}\right]=\left[\mathrm{Cl}^{-}\right]_{\text {ini }}-\mathrm{m} \cdot[\mathrm{Nd}]-3 \cdot[\overline{\mathrm{Nd}}]-\Delta\left[\mathrm{H}^{+}\right]$

where $\mathrm{m}$ can be $0,1,2$ or 3 , depending on the number of chlorides associated to the $\mathrm{Nd}(\mathrm{III})$ aqueous species. In the equation, $\mathrm{Cl}^{-}{ }_{\text {ini }}$ refers to the chloride concentration in the feed calculated as the sum of chloride concentration from $\mathrm{HCl}$ and $\mathrm{NaCl}$.

Subscripts are used to categorize the species of the process: ini indicates initial concentration and free is used to designate the extractant available after $\mathrm{HCl}$ and metal ions extraction. The bar over the species is used to denote that they are in the organic phase.

The equilibrium constant equations of the reactions above are linearized in terms of $[E]_{\text {free }}$. Table 4 shows, sorted by axis, the obtained linearizations, the theoretically expected slopes (T. Slope) and the slopes experimentally obtained (Exp. Slope). The experimental slopes were split into two groups regarding the concentration of chloride in the feed due to the effect of the anion on the extraction behaviour. This procedure is a handy guide to choosing which reaction proposed is the one that fits the experimental values.

Regarding the experimental slopes obtained and comparing them with the theoretical ones, it could be considered that the fitting of the $\mathrm{Nd}$ (III) extraction models depends on the chloride concentration in the aqueous phase. It has been observed that model b, whose stoichiometry metal:extractant is $1: 3$, is the most suitable model for $\mathrm{Nd}(\mathrm{III})$ extraction from low chloride solutions $\left(0.05 \mathrm{~mol} \cdot \mathrm{L}^{-1}\right)$ and model $\mathrm{f}$, whose stoichiometry metal:extractant is $1: 2$, is the most appropriate model for $\mathrm{Nd}(\mathrm{III})$ extraction from high chloride solutions ( 2 and $4 \mathrm{~mol} \cdot \mathrm{L}^{-1}$ ). The procedure followed to determine the fitting of the models performs the following steps:

Equilibrium equations $\mathrm{K}_{\mathrm{b}}$ from Eq. 4 and $\mathrm{K}_{\mathrm{f}}$ from Eq. 8 are taken as the starting point. Then the equilibrium equations are linearized taking logarithms.

Taking the linearization in terms of the expression $\mathrm{Y}=\mathrm{mX}+\mathrm{a}$ :

$$
\text { - Model b }
$$

$$
\begin{aligned}
& =\log \left(\frac{\left([\mathrm{Nd}]_{\text {ini }}-[\mathrm{Nd}]\right)}{[\mathrm{Nd}] \cdot\left(\left[\mathrm{Cl}^{-}\right]_{0}-3 \cdot\left([\mathrm{Nd}]_{\text {ini }}-[\mathrm{Nd}]\right)-\left(\left[\mathrm{H}^{+}\right]_{\text {ini }}-\left[\mathrm{H}^{+}\right]_{\text {eq }}\right.\right.}\right. \\
& \mathrm{X}=\log \left([\mathrm{E}]_{\text {free }}\right) \\
& =\log \left([\mathrm{E}]_{\text {ini }}-3 \cdot\left([\mathrm{Nd}]_{\text {ini }}-[\mathrm{Nd}]\right)\right. \\
& \left.\quad-\left(\left[\mathrm{H}^{+}\right]_{\text {ini }}-\left[\mathrm{H}^{+}\right]_{\text {eq }}\right)\right)
\end{aligned}
$$




$$
=\log \left(\frac{\left([\mathrm{Nd}]_{\text {ini }}-[\mathrm{Nd}]\right)}{[\mathrm{Nd}] \cdot\left(\left[\mathrm{Cl}^{-}\right]_{0}-3 \cdot\left([\mathrm{Nd}]_{\mathrm{ini}}-2 \cdot[\mathrm{Nd}]\right)-\left(\left[\mathrm{H}^{+}\right]_{\text {ini }}-\left[\mathrm{H}^{+}\right.\right.\right.}\right.
$$

$$
\begin{aligned}
X=\log \left([E]_{\text {free }}\right) & \\
=\log \left([E]_{\text {ini }}-2 \cdot\right. & \left([\mathrm{Nd}]_{\text {ini }}-[\mathrm{Nd}]\right) \\
& \left.-\left(\left[\mathrm{H}^{+}\right]_{\text {ini }}-\left[\mathrm{H}^{+}\right]_{\mathrm{eq}}\right)\right)
\end{aligned}
$$

Fig. 9 shows the representations of the experimental data values obtained by applying the expression $\mathrm{Y}=\mathrm{mX}+\mathrm{a}$ for the models $\mathrm{b}$ and $\mathrm{f}$ :

The linear regression analysis of the plot 10.a) shows a straight line with a slope $=2.90$ and $\mathrm{a} \mathrm{K}_{\mathrm{b}}=1.0 \cdot 10^{10}$. The linear regression analysis of the plot 10.b) shows a straight line with a slope $=2.01$ and a $\mathrm{K}_{\mathrm{f}}=5.5 \cdot 10^{3}$.

Fig. 10 shows the fitness of the calculated extraction percentages obtained using the models $\mathrm{b}$ and $\mathrm{f}$ with the experimental ones.

As can be seen, models $b$ and $f$ are able to recreate accurately the experimental extraction points achieved in low and high chloride media respectively. Even though the models do not take into account metal speciation in the aqueous phase, the results obtained show that they are reliable instruments to predict experimental data for this system.

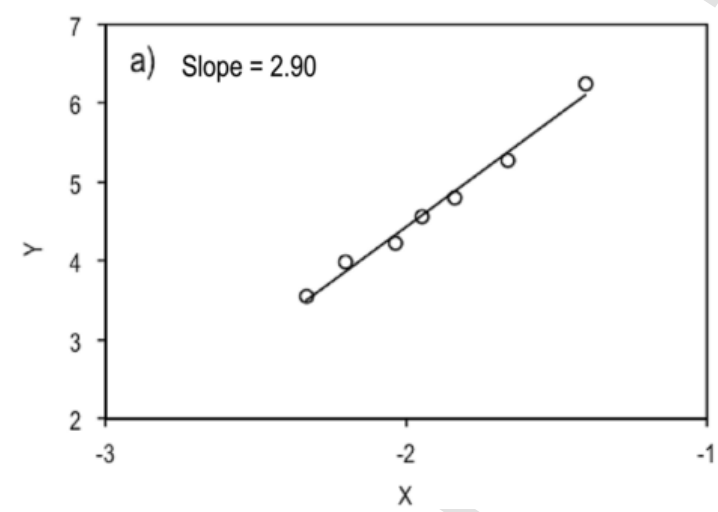

\section{Stripping studies}

Acidic solutions were tested for the stripping of $\mathrm{Nd}$ (III) from the loaded AliOle IL phase since they have been proven to strip metal ions efficiently from tetraoctylammonium oleate IL which is very similar to AliOle IL (Parmentier et al., 2015b). The metal ions can be easily stripped from the IL by acidic solutions because of the protonation of the oleate anion. Consequently, oleic acid is formed as well as a new IL, which could be methyl-tri(octyl/decyl)ammonium chloride, nitrate, sulfate or citrate, depending on the stripping solution used. Therefore, direct reuse of AliOle was impossible after stripping, but it was easily regenerated after washing it with $\mathrm{NaHCO}_{3}$ (Reaction R2). The use of oxalic acid as stripping agent was dismissed although it has been proven that it is able to strip $100 \%$ of $\mathrm{Nd}(\mathrm{III})$ from the organic phase without protonation of the oleate anion of the tetraoctylphosphonium oleate IL (Parmentier et al., 2015a). The stripping of Nd(III) with oxalic acid forms $\mathrm{Nd}(\mathrm{III})$-oxalate salts which are insoluble in the aqueous phase and since AliOle IL is addressed to an industrial application, the precipitation stripping is not the most appropriate option.

The acidic stripping of $\mathrm{Nd}(\mathrm{III})$ occurs according to the general reaction written in R19:

$$
\begin{aligned}
\overline{\left(\mathrm{R}_{4} \mathrm{~N}^{+} \mathrm{Cl}^{-}\right)_{(3-n)} \cdot \mathrm{MeCl}_{\mathrm{n}}{ }^{(3-n)+} \mathrm{A}_{(3-\mathrm{n})}}+\mathrm{HX} \\
\leftrightarrow \\
\quad(3-\mathrm{n}) \overline{\mathrm{R}_{4} \mathrm{~N}^{+} \mathrm{X}^{-}}+(3-\mathrm{n}) \overline{\mathrm{HA}} \\
\quad+3 \mathrm{Cl}^{-}+\mathrm{MeCl}_{\mathrm{n}}{ }^{(3-n)+}
\end{aligned}
$$

where $\overline{\left(\mathrm{R}_{4} \mathrm{~N}^{+} \mathrm{Cl}^{-}\right)_{(3-n)} \cdot \mathrm{MeCl}_{\mathrm{n}}{ }^{(3-\mathrm{n})+} \mathrm{A}_{(3-\mathrm{n})}}$ represents the IL-Me complex in the organic phase, $\mathrm{HX}$ an acid stripping solution, $\mathrm{MeCl}_{\mathrm{n}}^{(3-n)+}$

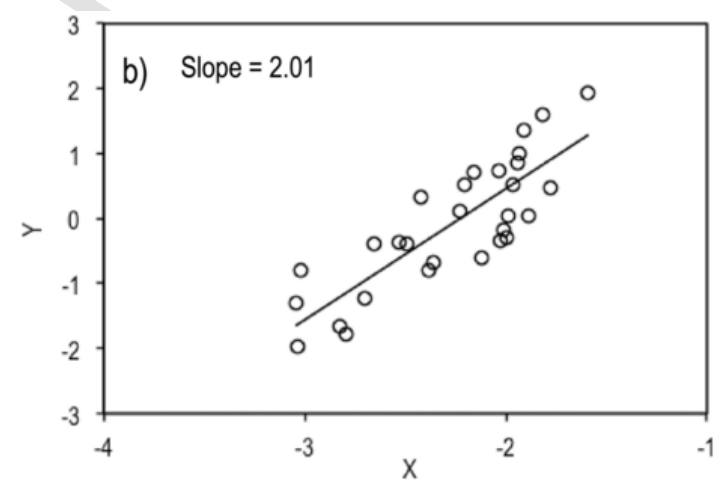

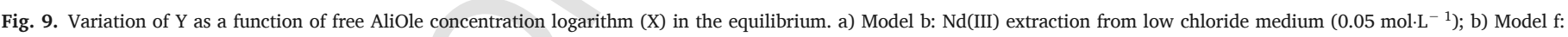
$\mathrm{Nd}(\mathrm{III})$ extraction from high chloride medium ( 2 and $\left.4 \mathrm{~mol} \cdot \mathrm{L}^{-1}\right)$.
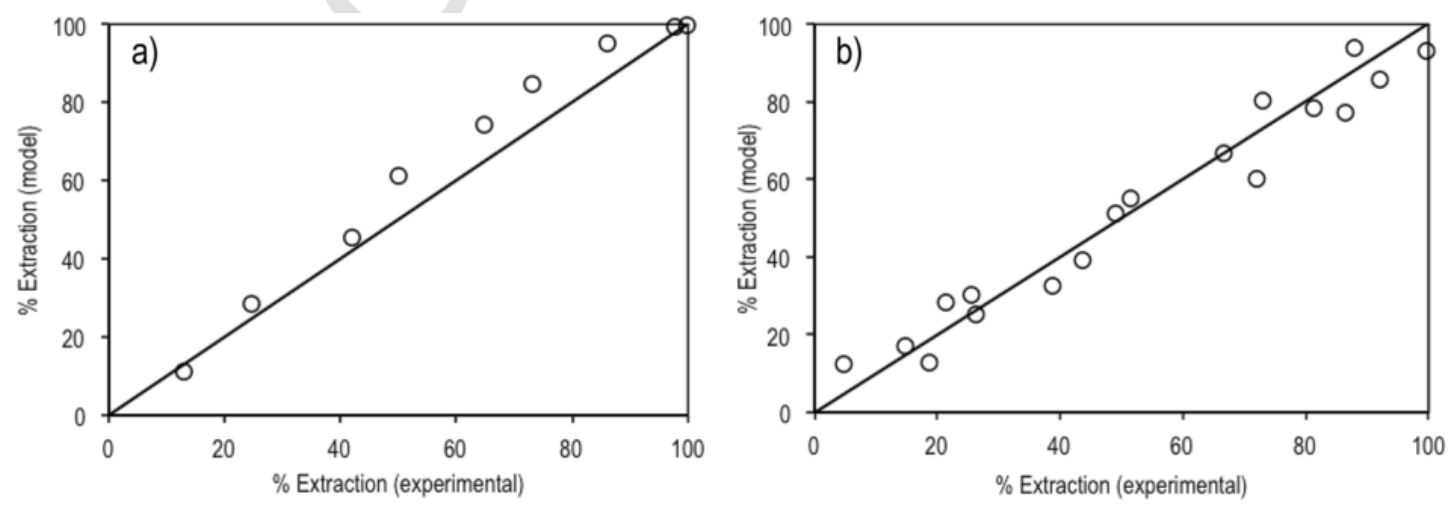

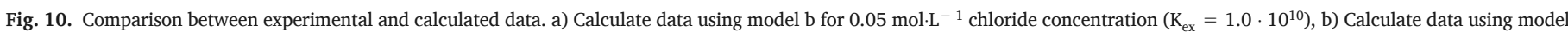
$\mathrm{f}$ for 2 and $4 \mathrm{~mol} \cdot \mathrm{L}^{-1}$ chloride concentrations $\left(\mathrm{K}_{\mathrm{ex}}=5.5 \cdot 10^{3}\right)$. 
Table 3

Linearized equilibria of the extraction reactions listed (11)-(20).

\begin{tabular}{|c|c|c|c|c|c|}
\hline Model & Axes & Logarithmic function represented & T. Slope & $\begin{array}{l}\text { Exp. Slope } \\
\mathrm{R}^{2}\end{array}$ & \\
\hline & & & & Low $\left[\mathrm{Cl}^{-}\right]$ & $\operatorname{High}\left[\mathrm{Cl}^{-}\right]$ \\
\hline a & Ordinate & $\log \left(\frac{\left(3 \cdot[\overline{\mathrm{Nd}}]+\Delta\left[\mathrm{H}^{+}\right]\right)^{3} \cdot[\overline{\mathrm{Nd}}]}{[\mathrm{Nd}] \cdot\left[\mathrm{Cl}^{-}\right]^{3}}\right)$ & 3 & $\begin{array}{l}4.61 \\
0.86\end{array}$ & $\begin{array}{l}3.64 \\
0.81\end{array}$ \\
\hline $\mathrm{b}$ & $\begin{array}{l}\text { Abscissa } \\
\text { Ordinate }\end{array}$ & $\begin{array}{l}\log \left([\mathrm{E}]_{\text {free }}\right) \\
\log \left(\frac{[\overline{\mathrm{Nd}}]}{[\mathrm{Nd}] \cdot\left[\mathrm{Cl}^{-}\right]^{3}}\right)\end{array}$ & 3 & $\begin{array}{l}2.90 \\
0.98\end{array}$ & $\begin{array}{l}2.05 \\
0.75\end{array}$ \\
\hline c & $\begin{array}{l}\text { Abscissa } \\
\text { Ordinate }\end{array}$ & $\begin{array}{l}\log \left([\mathrm{E}]_{\text {free }}\right) \\
\log \left(\frac{[\overline{\mathrm{Nd}}] \cdot\left([\overline{\mathrm{Nd}}]+\Delta\left[\mathrm{H}^{+}\right]\right)}{[\mathrm{Nd}] \cdot\left[\mathrm{Cl}^{-}\right]^{3}}\right)\end{array}$ & 3 & $\begin{array}{l}3.74 \\
0.82\end{array}$ & $\begin{array}{l}2.54 \\
0.82\end{array}$ \\
\hline d & $\begin{array}{l}\text { Abscissa } \\
\text { Ordinate }\end{array}$ & $\begin{array}{l}\log \left([\mathrm{E}]_{\text {free }}\right) \\
\log \left(\frac{[\overline{\mathrm{Nd}}] \cdot\left(2 \cdot[\overline{\mathrm{Nd}}]+\Delta\left[\mathrm{H}^{+}\right]\right)^{2}}{[\mathrm{Nd}] \cdot\left[\mathrm{Cl}^{-}\right]^{3}}\right)\end{array}$ & 3 & $\begin{array}{l}4.25 \\
0.90\end{array}$ & $\begin{array}{l}3.49 \\
0.67\end{array}$ \\
\hline e & $\begin{array}{l}\text { Abscissa } \\
\text { Ordinate }\end{array}$ & $\begin{array}{l}\log \left([\mathrm{E}]_{\text {free }}\right) \\
\log \left(\frac{\left(2 \cdot[\overline{\mathrm{Nd}}]+\Delta\left[\mathrm{H}^{+}\right]\right)^{2} \cdot[\overline{\mathrm{Nd}}]}{[\mathrm{Nd}] \cdot\left[\mathrm{Cl}^{-}\right]^{2}}\right)\end{array}$ & 2 & $\begin{array}{l}4.36 \\
0.87\end{array}$ & $\begin{array}{l}3.22 \\
0.74\end{array}$ \\
\hline $\mathrm{f}$ & $\begin{array}{l}\text { Abscissa } \\
\text { Ordinate }\end{array}$ & $\begin{array}{l}\log \left([\mathrm{E}]_{\mathrm{free}}\right) \\
\log \left(\frac{[\overline{\mathrm{Nd}}]}{[\mathrm{Nd}] \cdot\left[\mathrm{Cl}^{-}\right]^{2}}\right)\end{array}$ & 2 & $\begin{array}{l}2.92 \\
0.89\end{array}$ & $\begin{array}{l}2.01 \\
0.96\end{array}$ \\
\hline $\mathrm{g}$ & $\begin{array}{l}\text { Abscissa } \\
\text { Ordinate }\end{array}$ & $\begin{array}{l}\log \left([\mathrm{E}]_{\text {free }}\right) \\
\log \left(\frac{[\overline{\mathrm{Nd}}] \cdot\left([\overline{\mathrm{Nd}}]+\Delta\left[\mathrm{H}^{+}\right]\right)}{[\mathrm{Nd}] \cdot\left[\mathrm{Cl}^{-}\right]^{2}}\right)\end{array}$ & 2 & $\begin{array}{l}3.76 \\
0.71\end{array}$ & $\begin{array}{l}2.50 \\
0.85\end{array}$ \\
\hline $\mathrm{h}$ & $\begin{array}{l}\text { Abscissa } \\
\text { Ordinate }\end{array}$ & $\begin{array}{l}\log \left([\mathrm{E}]_{\text {free }}\right) \\
\log \left(\frac{\left([\overline{\mathrm{Nd}}]+\Delta\left[H^{+}\right]\right) \cdot[\overline{\mathrm{Nd}}]}{[\mathrm{Nd}] \cdot\left[\mathrm{Cl}^{-}\right]}\right.\end{array}$ & 1 & $\begin{array}{l}3.29 \\
0.69\end{array}$ & $\begin{array}{l}1.40 \\
0.73\end{array}$ \\
\hline $\mathrm{i}$ & $\begin{array}{l}\text { Abscissa } \\
\text { Ordinate }\end{array}$ & $\begin{array}{l}\log \left([\mathrm{E}]_{\mathrm{free}}\right) \\
\log \left(\frac{[\overline{\mathrm{Nd}}]}{[\mathrm{Nd}] \cdot\left[\mathrm{Cl}^{-}\right]}\right)\end{array}$ & 1 & $\begin{array}{l}2.37 \\
0.81\end{array}$ & $\begin{array}{l}2.59 \\
0.88\end{array}$ \\
\hline $\mathrm{j}$ & $\begin{array}{l}\text { Abscissa } \\
\text { Ordinate }\end{array}$ & $\begin{array}{l}\log \left([\mathrm{E}]_{\text {free }}\right) \\
\log \left(\frac{[\mathrm{N \textrm {Nd }}]}{[\mathrm{Nd}]}\right)\end{array}$ & 1 & $\begin{array}{l}3.08 \\
0.93\end{array}$ & $\begin{array}{l}2.21 \\
0.91\end{array}$ \\
\hline & Abscissa & $\log \left([\mathrm{E}]_{\text {free }}\right)$ & & & \\
\hline
\end{tabular}

Table 4

Stripping extension obtained after a single contact with $\mathrm{HCl}, \mathrm{HNO}_{3}, \mathrm{H}_{2} \mathrm{SO}_{4}$ and citric acid $0.5 \mathrm{~mol} \cdot \mathrm{L}^{-1}$ for neodymium solutions ( $1000 \mathrm{mg} \cdot \mathrm{L}^{-1} ; 7^{*} 10^{-3} \mathrm{~mol} \cdot \mathrm{L}^{-1}$ ) in $2 \mathrm{~mol} \cdot \mathrm{L}^{-1} \mathrm{Cl}^{-}$. Shaking time $=15 \mathrm{~min}$ at room temperature. Organic phase: [AliOle] $=0.02 \mathrm{~mol} \cdot \mathrm{L}^{-1}$. $[\mathrm{Nd}(\mathrm{III})]$ loaded in the organic phase after extraction was $650 \mathrm{mg} \cdot \mathrm{L}^{-1}$.

\begin{tabular}{ll}
\hline Stripping agent & \% Stripping \\
\hline $\mathrm{HCl}$ & 33.2 \\
$\mathrm{HNO}_{3}$ & 36.0 \\
$\mathrm{H}_{2} \mathrm{SO}_{4}$ & 33.4 \\
Citric acid & 32.6 \\
\hline
\end{tabular}

embraces all neodymium chloride species and $\mathrm{n}$ could be any value in the range $0-3$.

Stripping of the metal ions was investigated using $\mathrm{HCl}, \mathrm{HNO}_{3}$, $\mathrm{H}_{2} \mathrm{SO}_{4}$, and citric acid solutions. Table 3 shows the stripping yields achieved after neodymium extraction with AliOle $0.02 \mathrm{~mol} \cdot \mathrm{L}^{-1}$.

As can be seen in Table 4, the stripping percentages obtained using different acidic agents after the first contact were practically identical. So, the strength of the acids has not a particular effect on the back extraction. On the other hand, the complexing power of the citric acid is proved to be appropriate for the stripping purpose. Three stripping contacts were required to achieve a $\mathrm{Nd}(\mathrm{III})$ stripping percentage $>90 \%$ with all the stripping agents.

The effect of the stripping solution acidity was also tested. $\mathrm{HCl}$ solutions at concentrations in the range $0.05-6 \mathrm{~mol} \cdot \mathrm{L}^{-1}$ were used. $\mathrm{HCl}$ was chosen among the rest of acidic solutions in order to avoid the mixture of anions in the system. Fig. 11 shows the effect of $\mathrm{HCl}$ concentrations on the stripping extension after the first contact.

As can be observed, the increase of hydrochloric acid concentration does not have a significant effect on the stripping extension. Thus, low hydrochloric acid solutions can be used to strip the metal ions from the organic phase.

\section{Conclusions}

This paper reports on the extraction of neodymium(III) from chloride media. First of all, the effect of different types of extractants has been studied and ionic liquids Cyphos 104, AliCy, AliDec, AliD2EHPA and AliOle have shown the best extraction potential. Although they all share a similar behaviour, AliOle IL has been chosen to carry out a detailed extraction study due to its high extraction ability and its easy separation of phases. The effect of the AliOle concentration was favoured by increasing it in the range 0.05 to $0.1 \mathrm{~mol} \cdot \mathrm{L}^{-1}$. The initial $\mathrm{pH}$ of the feed was fixed at 3.5 to maintain the equilibrium $\mathrm{pH}$ in the range 5-6.5.

The effect of chloride concentration was also studied and it was seen that high chloride concentration in the aqueous phase increases the $\mathrm{Nd}(\mathrm{III})$ extraction by promoting $\mathrm{Nd}-\mathrm{Cl}$ complex formation. The $\mathrm{Nd}(\mathrm{III})$ recovery was completed after three stripping contacts with $\mathrm{HCl}$. Two Nd(III) extraction models, that include $\mathrm{HCl}$ competitive extraction with the metal ions, were proposed. According to the models, $\mathrm{Nd}(\mathrm{III})-$ AliOle extraction mechanism depends on the chloride concentration in the aqueous phase. The models assume extraction of $\mathrm{Nd}^{3+}$ species $\left(\mathrm{K}_{\mathrm{ex}}=1.0 \cdot 10^{10}\right)$ at low chloride concentrations (model $\mathrm{b}$ ) and $\mathrm{NdCl}^{2}+$ species $\left(\mathrm{K}_{\mathrm{ex}}=5.5 \cdot 10^{3}\right)$ when the chloride concentration is $>2 \mathrm{~mol} \cdot \mathrm{L}^{-1}$ (model $\mathrm{f}$ ). The models are able to reproduce accurately 


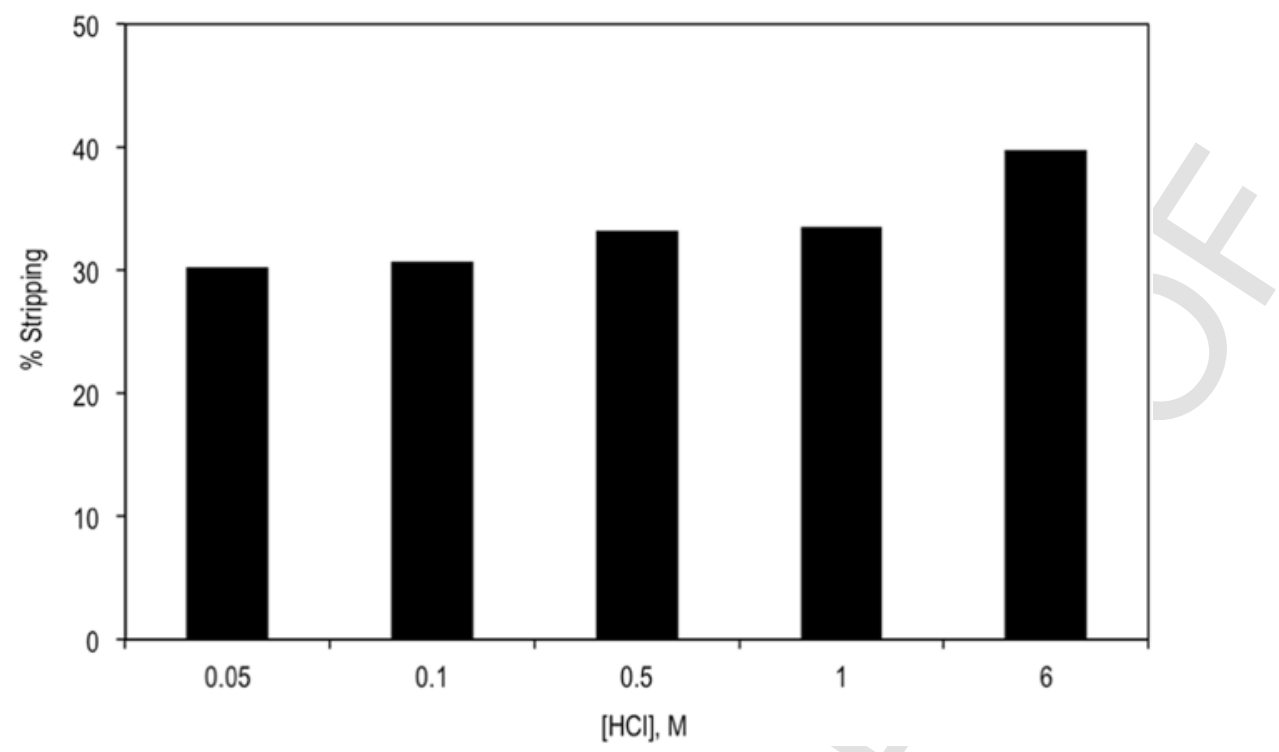

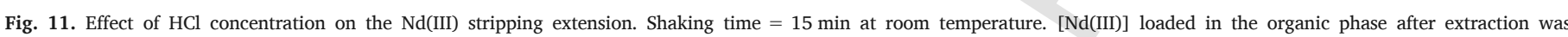
$650 \mathrm{mg} \cdot \mathrm{L}^{-1}$.

the experimental $\mathrm{Nd}(\mathrm{III})$ extraction extension and predict the extraction behaviour at other conditions.

\section{Acknowledgements}

This work was supported by the Ministry of Science and Innovation of Spain (Project No. CTM 2014-52770-R). E.O. acknowledges The Ministry of Science and Innovation the fellowship received (BES-2012-057589).

\section{References}

Banda, R., Jeon, H.S., Lee, M.S., 2015. Separation of Nd from mixed chloride solutions with Pr by extraction with saponified PC 88A and scrubbing. J. Ind. Eng. Chem. 21, 436-442. https://doi.org/10.1016/j.jiec.2014.03.002.

Behera, S.S., Parhi, P.K., 2016. Leaching kinetics study of neodymium from the scrap magnet using acetic acid. Sep. Purif. Technol. 160, 59-66. https://doi.org/10.1016/j. seppur.2016.01.014.

Cevasco, G., Chiappe, C., 2014. Are ionic liquids a proper solution to current environmental challenges?. Green Chem. 16, 2375. https://doi.org/10.1039/c3gc42096e.

Coll, M.T., Fortuny, A., Sastre, A.M., 2014. Boron reduction by supported liquid membranes using ALiCY and ALiDEC ionic liquids as carriers. Chem. Eng. Res. Des. 92, 758-763. https://doi.org/10.1016/j.cherd.2013.11.010.

Dupont, D., Binnemans, K., 2015. Recycling of Rare Earths From NdFeB Magnets Using a Combined Leaching/Extraction System Based on the Acidity and Thermomorphism osf the Ionic Liquid [Hbet][Tf2N]. 17, 2150-2163. https://doi.org/10.1039/c5gc00155b.

El-Nadi, Y.A., 2012. Lanthanum and neodymium from Egyptian monazite: synergistic extractive separation using organophosphorus reagents. Hydrometallurgy 119-120, 23-29. https://doi.org/10.1016/j.hydromet.2012.03.003.

European Commission, 2010. Critical raw materials for the EU. In: Report of the Ad-hoc Working Group on defining critical raw materials. 39, Eucom, pp. 1-84.

European Commission, 2014. ERECON: Strengthening the European Rare Earths Supply-Chain, Challenges and Policy Options.

European Commission, 2014. Report on critical raw materials for the EU. In: Report of the Ad-hoc Working Group on Defining Critical Raw Materials.

Fortuny, A., Coll, M.T., Sastre, A.M., 2012. Use of methyltrioctyl/decylammonium bis 2,4,4-(trimethylpentyl)phosphinate ionic liquid (ALiCY IL) on the boron extraction in chloride media. Sep. Purif. Technol. 97, 137-141. https://doi.org/10.1016/j.seppur. 2012.02.037.

Högfeldt, E., 1982. Stability constants of metal-ion complexes, part a: inorganic ligands. In: IUPAC Chemical Data Series. Pergamon Presshttps://doi.org/10.1002/bbpc. 19830871236

Itoh, M., Miura, K., Machida, K., 2009. Novel rare earth recovery process on Nd-Fe-B magnet scrap by selective chlorination using NH4Cl. J. Alloys Compd. 477, 484-487. https://doi.org/10.1016/j.jallcom.2008.10.036.

Lee, M.-S., Lee, J.-Y., Kim, J.-S., Lee, G.-S., 2005. Solvent extraction of neodymium ions from hydrochloric acid solution using PC88A and saponified PC88A. Sep. Purif. Technol. 46, 72-78. https://doi.org/10.1016/j.seppur.2005.04.014.
Panda, N., Devi, N., Mishra, S., 2012. Solvent extraction of neodymium(III) from acidic nitrate medium using Cyanex 921 in kerosene. J. Rare Earths 30, 794-797. https:// doi.org/10.1016/S1002-0721(12)60132-X.

Parmentier, D., Valia, Y.A., Metz, S.J., Burheim, O.S., Kroon, M.C., 2015. Regeneration of the ionic liquid tetraoctylammonium oleate after metal extraction. Hydrometallurgy 158, 56-60. https://doi.org/10.1016/j.hydromet.2015.10.006.

Parmentier, D., Vander Hoogerstraete, T., Metz, S.J., Binnemans, K., Kroon, M.C., 2015 Selective extraction of metals from chloride solutions with the tetraoctylphosphonium oleate ionic liquid. Ind. Eng. Chem. Res. 54, 5149-5158. https://doi.org/10.1021/acs. iecr.5b00534.

Puigdomenech, I., 2013. Medusa Software.

Rout, A., Binnemans, K., 2014. Solvent Extraction of Neodymium(III) by Functionalized Ionic Liquid Trioctylmethylammonium Dioctyl Diglycolamate in Fluorine-free Ionic Liquid Diluent. 53, 6500-6508. https://doi.org/10.1021/ie404340p.

Rout, A., Binnemans, K., 2015. Influence of the ionic liquid cation on the solvent extraction of trivalent rare-earth ions by mixtures of Cyanex 923 and ionic liquids. Dalton Trans. 44, 1379-1387. https://doi.org/10.1039/c4dt02766c.

Rout, A., Kotlarska, J., Dehaen, W., Binnemans, K., 2013. Liquid-liquid extraction of neodymium(III) by dialkylphosphate ionic liquids from acidic medium: the importance of the ionic liquid cation. Phys. Chem. Chem. Phys. 15, 16533-16541. https:// doi.org/10.1039/c3cp52218k.

Sastri, V.S., Bünzli, J.C., Perumareddi, J.R., Rao, V.R., Rayudu, G.V.S., 2003. Modern Aspects of Rare Earths and their Complexes. Elsevier.

Smith Stegen, K., 2015. Heavy rare earths, permanent magnets, and renewable energies: an imminent crisis. Energ Policy 79, 1-8. https://doi.org/10.1016/j.enpol.2014.12. 015 .

Tunsu, C., Petranikova, M., Gergorić, M., Ekberg, C., Retegan, T., 2015. Reclaiming rare earth elements from end-of-life products: a review of the perspectives for urban mining using hydrometallurgical unit operations. Hydrometallurgy 156, 239-258. https: //doi.org/10.1016/j.hydromet.2015.06.007.

Vander Hoogerstraete, T., Blanpain, B., Van Gerven, T., Binnemans, K., 2014. From NdFeB magnets towards the rare-earth oxides: a recycling process consuming only oxalic acid. RSC Adv. 4, 64099-64111. https://doi.org/10.1039/C4RA13787F.

Wang, X., Lei, Y., Ge, J., Wu, S., 2015. Production forecast of China's rare earths based on the generalized Weng model and policy recommendations. Res. Policy 43, 11-18. https://doi.org/10.1016/j.resourpol.2014.11.002.

Wang, J., Zhao, J., Feng, D., Kang, X., Sun, Y., Zhao, L., Liang, H., 2016. Enhancing extraction ability by rational design of phosphoryl functionalized ionic liquids and mechanistic investigation on neodymium (III) extraction. J. Rare Earths 34, 83-90. https:// doi.org/10.1016/S1002-0721(14)60579-2.

Wannachod, T., Leepipatpiboon, N., Pancharoen, U., Nootong, K., 2014. Separation and mass transport of $\mathrm{Nd}(\mathrm{III})$ from mixed rare earths via hollow fiber supported liquid membrane: experiment and modeling. Chem. Eng. J. 248, 158-167. https://doi.org/ 10.1016/j.cej.2014.03.024.

Wübbeke, J., 2013. Rare earth elements in China: policies and narratives of reinventing an industry. Res. Policy 38, 384-394. https://doi.org/10.1016/j.resourpol.2013.05.005.

Xie, F., Zhang, T.A., Dreisinger, D., Doyle, F., 2014. A critical review on solvent extraction of rare earths from aqueous solutions. Miner. Eng. 56, 10-28. https://doi.org/10. 1016/j.mineng.2013.10.021.

Yoon, H.-S., Kim, C.-J., Chung, K.-W., Kim, S.-D., Lee, J.-Y., Kumar, J.R., 2016. Solvent extraction, separation and recovery of dysprosium (Dy) and neodymium (Nd) from aqueous solutions: waste recycling strategies for permanent magnet processing. Hydrometallurgy https://doi.org/10.1016/j.hydromet.2016.01.028. 
Zhang, L., Guo, Q., Zhang, J., Huang, Y., Xiong, T., 2015. Did China's rare earth export policies work? - empirical evidence from USA and Japan. Res. Policy 43, 82-90. https://doi.org/10.1016/j.resourpol.2014.11.007. 